\title{
Characteristics of Mesoscale Organization in WRF Simulations of Convection during TWP-ICE
}

\author{
Anthony D. Del Genio \\ NASA Goddard Institute for Space Studies, New York, New York \\ Jingbo Wu AND YonghuA CHEN \\ Department of Applied Physics and Applied Mathematics, Columbia University, New York, New York
}

(Manuscript received 6 August 2011, in final form 4 February 2012)

\begin{abstract}
Compared to satellite-derived heating profiles, the Goddard Institute for Space Studies general circulation model (GCM) convective heating is too deep and its stratiform upper-level heating is too weak. This deficiency highlights the need for GCMs to parameterize the mesoscale organization of convection. Cloudresolving model simulations of convection near Darwin, Australia, in weak wind shear environments of different humidities are used to characterize mesoscale organization processes and to provide parameterization guidance. Downdraft cold pools appear to stimulate further deep convection both through their effect on eddy size and vertical velocity. Anomalously humid air surrounds updrafts, reducing the efficacy of entrainment. Recovery of cold pool properties to ambient conditions over 5-6 h proceeds differently over land and ocean. Over ocean increased surface fluxes restore the cold pool to prestorm conditions. Over land surface fluxes are suppressed in the cold pool region; temperature decreases and humidity increases, and both then remain nearly constant, while the undisturbed environment cools diurnally. The upper-troposphere stratiform rain region area lags convection by $5-6 \mathrm{~h}$ under humid active monsoon conditions but by only $1-2 \mathrm{~h}$ during drier break periods, suggesting that mesoscale organization is more readily sustained in a humid environment. Stratiform region hydrometeor mixing ratio lags convection by $0-2 \mathrm{~h}$, suggesting that it is strongly influenced by detrainment from convective updrafts. Small stratiform region temperature anomalies suggest that a mesoscale updraft parameterization initialized with properties of buoyant detrained air and evolving to a balance between diabatic heating and adiabatic cooling might be a plausible approach for GCMs.
\end{abstract}

\section{Introduction}

The problem of representing moist convection in general circulation models (GCMs) has historically used the paradigm of an ensemble of convective cells (e.g., Arakawa and Schubert 1974). Since the Global Atmospheric Research Program Atlantic Tropical Experiment (GATE) in 1974, however, it has been realized that convective cells are often organized into mesoscale clusters with large precipitating stratiform regions that evolve differently (Houze and Betts 1981).

Mesoscale convective systems represent only about $10 \%$ of all tropical storms but account for $80 \%-85 \%$ of rainfall (Del Genio and Kovari 2002). Stratiform rain

Corresponding author address: Anthony D. Del Genio, NASA Goddard Institute for Space Studies, 2880 Broadway, New York, NY 10025.

E-mail: anthony.d.delgenio@nasa.gov accounts for much of the raining area and $\sim 40 \%$ of the total precipitation (Schumacher and Houze 2003). Over the life cycle of mesoscale clusters, rain evolves from more convective to more stratiform (Houze 1989; Futyan and Del Genio 2007), accompanied by a shift in diabatic heating from first baroclinic mode full-troposphere heating to second baroclinic mode heating in the upper troposphere and cooling below (Houze 1989). This is due to the development of mesoscale updrafts at high altitudes, deposition growth of sedimenting ice particles, melting, and low-level rain evaporation, leading to mesoscale downdrafts (Zipser 1977; Biggerstaff and Houze 1991). This upward shift in heating affects the Walker circulation (Schumacher et al. 2004) and convectively coupled waves (Mapes et al. 2006).

Mesoscale organization of convection is equally important radiatively. Convective storms regulate the tropical planetary albedo and outgoing longwave radiation; $65 \%-75 \%$ of their effect comes from mesoscale clusters 

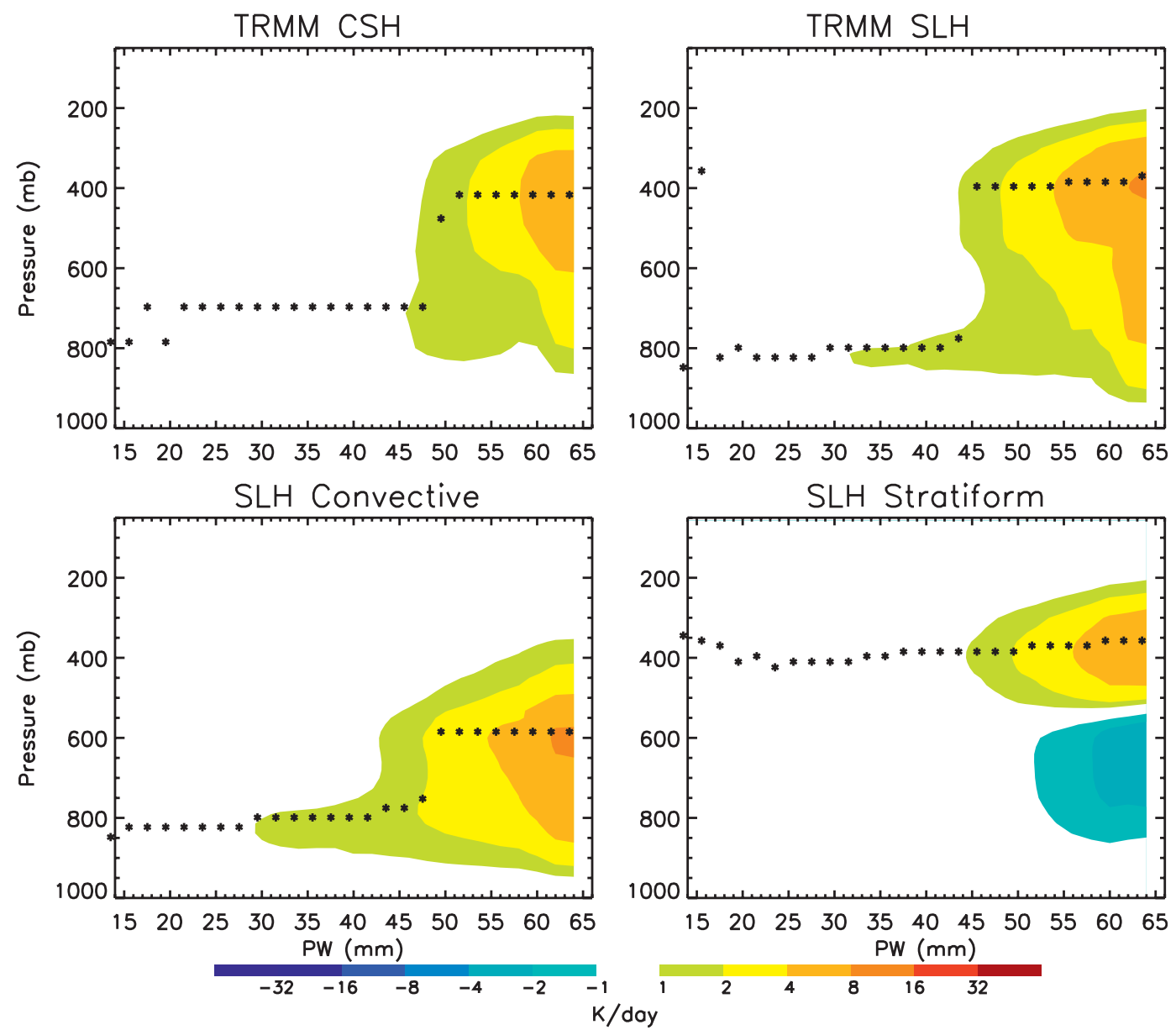

FIG. 1. TRMM Precipitation Radar heating profiles composited by TRMM Microwave Imager PW vapor over the tropical Indian and west Pacific Oceans. Total (top left) CSH and (top right) SLH heating. Partitioning of SLH into (bottom left) convective and (bottom right) stratiform components. Dots represent the altitude of peak heating for each value of PW.

(Del Genio and Kovari 2002). Mesoscale convective events significantly moisten the upper troposphere (Zelinka and Hartmann 2009). The stratiform rain region and anvil contribute little to water vapor feedback (Del Genio et al. 1991), but they are important to cloud feedback (Yao and Del Genio 1999; Zelinka and Hartmann 2010). The radiative heating profile in the stratiform rain and anvil regions can stabilize/destabilize different altitudes and affect vertical motions (Ackerman et al. 1988; Jensen and Del Genio 2003; Mather and McFarlane 2009; L'Ecuyer and McGarrah 2010).

Despite their importance, mesoscale updrafts and downdrafts are still not represented in most GCMs with one exception (Donner 1993; Donner et al. 2001), although several other approaches have been proposed (Alexander and Cotton 1998; Gray 2000). Many GCMs detrain ice from convective updrafts into anvils, but by itself this is not likely to produce a realistic vertical distribution of heating or its evolution with time. We demonstrate this using Tropical Rainfall Measuring Mission (TRMM) Precipitation Radar convective heating products. Figure 1 (top panels) shows two independent estimates of tropical heating composited by precipitable water (PW), from the convective-stratiform heating ( $\mathrm{CSH})$ algorithm (Tao et al. 2001) and from the spectral latent heating (SLH) algorithm (Shige et al. 2007). The two represent slightly different quantities (total diabatic heating for CSH; total diabatic minus radiative heating for SLH) but have similar structures, with a transition to a deep heating profile at $\mathrm{PW} \sim 45 \mathrm{~mm}$ and a heating peak near $400 \mathrm{hPa}$ at higher PW. The CSH vertical profile has less low-level heating than SLH at high PW, and SLH also has a significant shallow convective heating signature at low PW that is weak in CSH, consistent with the findings of Hagos et al. (2010). SLH also separates the heating into convective and stratiform components (Fig. 1, bottom panels). 

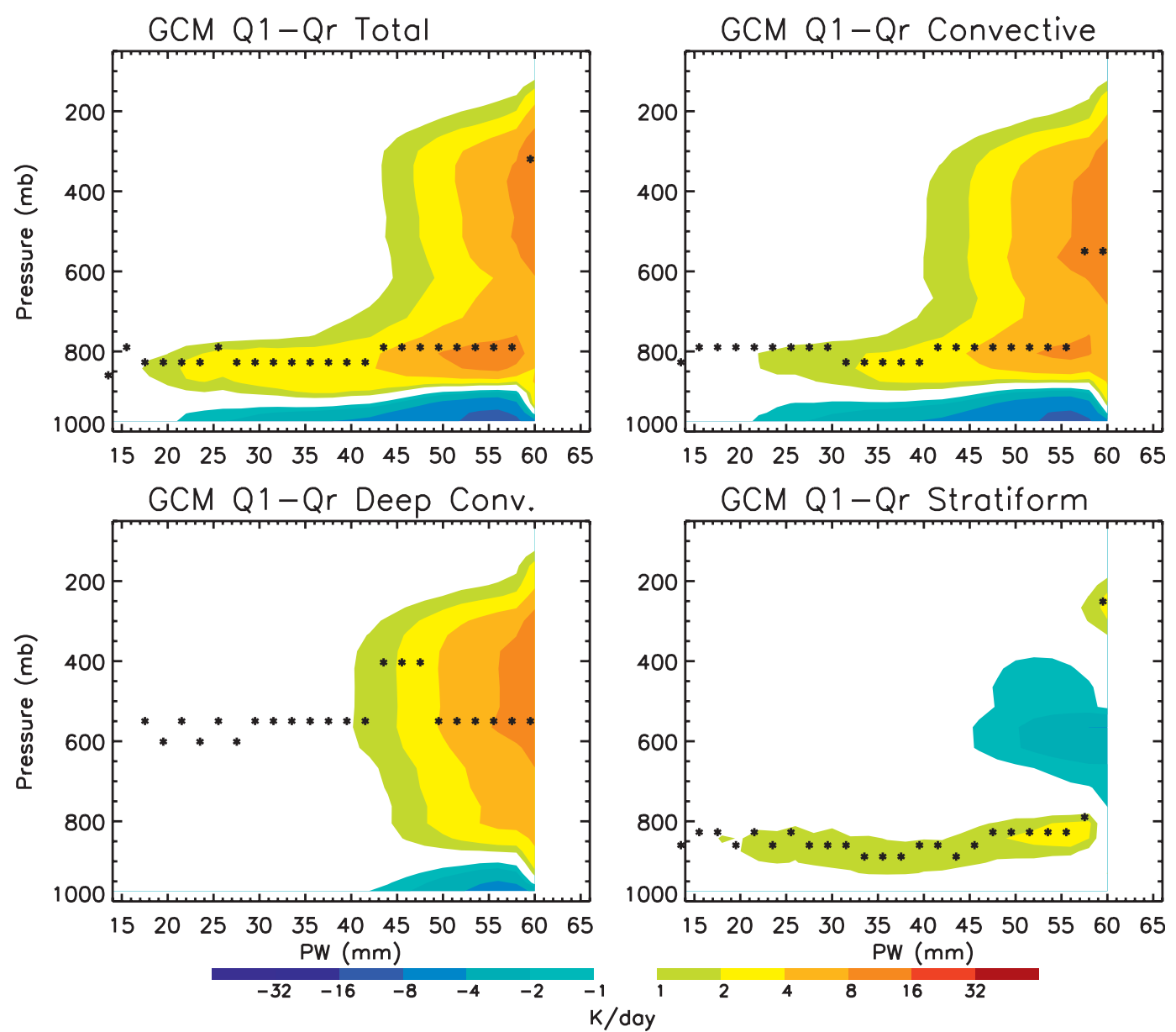

FIG. 2. As in Fig. 1, but for GISS GCM (top left) total diabatic-minus-radiative heating, (top right) convective heating, (bottom left) deep convective heating, and (bottom right) stratiform heating.

The convective heating peaks near $600 \mathrm{hPa}$ and heating rates $>1 \mathrm{~K} \mathrm{day}^{-1}$ reach $350 \mathrm{hPa}$ in the wettest environments. The stratiform component shows the dipole structure seen in field experiments: Upper-level heating due to mesoscale updraft condensation, and a broad cooling region below the melting level due to melting of snow and evaporation of rain.

Figure 2 shows heating profiles due to parameterized convection and anvils (Del Genio et al. 1996, 2005, 2007) in the Goddard Institute for Space Studies (GISS) Model E2 GCM (G. A. Schmidt et al. 2012, unpublished manuscript). Total heating (top-left panel) resembles that retrieved from TRMM data, especially SLH, but the GCM has more shallow heating and boundary layer cooling. However, convective heating (top-right panel), and specifically that due to deep convective events (bottom-left panel), extends much too high. This compensates for almost nonexistent upper-level stratiform heating (bottomright panel) and a cooling signature that peaks too high and is dominated by melting rather than rain evaporation.
Since the convective and stratiform components dominate at different stages of the life cycle, the shortcomings in Fig. 2 have significant consequences. GCMs produce peak continental precipitation near noon, much earlier than observed (Dai 2006). This is partly due to the premature triggering of deep convection or weak entrainment (Guichard et al. 2004; Rio et al. 2009; Del Genio and Wu 2010), but the absence of mesoscale organization, which extends the lifetime of convective systems beyond the decay time of individual convective events, prevents significant precipitation later in the day. This error implies that the shortwave effect of convection is biased high (since cloudiness erroneously peaks at low solar zenith angle), while the effect of convection on soil moisture is biased low (since surface rain near noon is more likely to evaporate than infiltrate). The staggered timing of the convective and stratiform heating profiles also affects convectively coupled tropical waves, which in many theories depends on time-varying first and second baroclinic modes (Mapes 2000; Mapes et al. 2006). The most 
notable evidence of this GCM deficiency is the MaddenJulian oscillation, which is simulated poorly by many models (Lin et al. 2006; Kim et al. 2009).

Organization is inherently about temporal evolution and thus requires new prognostic variables in GCMs to represent unresolved mesoscale quantities in terms of the parent convection and the environment in which it resides. In this paper we use a cloud-resolving model (CRM) to glean information about organization that might form the basis for a future parameterization. Section 2 describes the model and the simulations performed, as well as a classification scheme we employ to characterize different regions of the mesoscale cluster. Organization is a two-part problem. The first part involves the downdraft cold pools that generate the nextgeneration convection that continues the supply of water to the upper troposphere (e.g., Zipser 1977); these are discussed in section 3 . The second part concerns the formation and evolution of the stratiform precipitation region, which we explore in section 4 . Section 5 discusses the implications of our results for the parameterization of organization in a GCM.

\section{Model and simulations}

\section{a. WRF model}

We use the Advanced Research Weather Research and Forecasting model, version 3.2 (WRF V3.2). WRF V3.2 employs an Eulerian solver for the fully compressible nonhydrostatic equations and complete Coriolis and curvature terms (Skamarock et al. 2008). It uses Arakawa C-grid staggering, and the vertical coordinate is terrain-following dry hydrostatic pressure. The model top is a constant pressure surface. Prognostic variables are in scalar-conserving flux form.

Moist convection is resolved in our control simulations (section $2 \mathrm{~b}$ ), which do not use a cumulus parameterization. Subgrid boundary layer turbulence is based on the Mellor-Yamada-Janjić scheme (Janjić 2002). The parameterization updates the turbulent kinetic energy with the production/dissipation term and the vertical diffusion term from the Mellor-Yamada level 2.5 turbulence closure model as extended by Janjić. Exchange coefficients for the surface and all layer interfaces are computed from the Monin-Obukhov theory. The land surface is represented by the Noah land surface model (LSM), the successor to the Oregon State University (OSU) LSM described by Chen and Dudhia (2001). Noah, a four-layer soil temperature and moisture model with canopy moisture and snow cover prediction, provides sensible and latent heat fluxes to the boundary layer scheme. Noah also has an improved urban treatment and considers surface emissivity properties (Skamarock et al. 2008). The surface layer parameterization is the Monin-Obukhov (Janjić) scheme (Janjić 2002). It generates the surface exchange coefficients for vertical turbulent exchange based on the Monin-Obukhov theory with various refinements. Longwave radiation uses the Rapid Radiative Transfer Model (RRTM) (Mlawer et al. 1997), a spectral band scheme using the correlated$k$ method. Shortwave radiation is parameterized using the Goddard scheme based on Chou and Suarez (1994). It has 11 spectral bands and considers diffuse and direct solar radiation components in a two-stream approach that accounts for scattered and reflected components.

For modeling mesoscale convective organization, perhaps the greatest uncertainty is cloud microphysics, especially treatment of the ice phase. We therefore use two very different microphysics parameterizations to distinguish robust from model-dependent features. One is the single-moment version of the Morrison et al. (2009) scheme, a bulk scheme that predicts mixing ratios of cloud droplets, cloud ice, rain, snow, and graupel. The other is the Thompson et al. (2008) scheme, which includes the same species but has two-moment cloud ice and rain. The Thompson et al. parameterization is intended for use in winter weather forecasting and aviation applications in which concerns about such things as aircraft icing arise, and thus focuses more on maintenance of supercooled liquid water than schemes designed to simulate convective systems.

\section{b. Simulation design}

We conduct simulations of the active monsoon and monsoon break periods during the Tropical Warm PoolInternational Cloud Experiment (TWP-ICE) conducted near Darwin, Australia, in 2006 (May et al. 2008). The simulation design is based on that described in $\mathrm{Wu}$ et al. (2009) and identical to that of the control run in Del Genio and $\mathrm{Wu}$ (2010), who used an earlier version of WRF to study convective updrafts and entrainment. The simulation domain is $\sim 280 \mathrm{~km} \times 280 \mathrm{~km}$, centered on Darwin at $600-\mathrm{m}$ resolution with 50 vertical layers and realistic geography [Bryan et al. (2003) recommend a resolution of $\sim 100 \mathrm{~m}$ for deep convection, but Del Genio and Wu (2010) and Romps and Kuang (2010) find that the coarser resolution produces similar results except for slightly weaker entrainment and mass flux]. The model is driven by 6-h-resolution European Centre for Medium-Range Weather Forecasts (ECMWF) winds at the boundaries, but the temperature and humidity advected into the domain are specified from TWP-ICE sounding array observations and the constrained variational analysis of Xie et al. (2010). ECMWF also provides prescribed sea surface temperatures. 
How best to force CRMs for particular scientific purposes is uncertain. Several TWP-ICE model intercomparisons have already been performed using different approaches. Varble et al. (2011) and Fridlind et al. (2012) force CRMs directly with the Xie et al. (2010) advective forcing and apply periodic boundary conditions. One concern they raise with this approach is that the simulated convective area decays more slowly than observed, due to the periodic boundary conditions that do not allow systems to pass out of the domain. Since we wish to understand the temporal relationships between the convective and stratiform regions, we chose not to pursue this method. Zhu et al. (2012) compare limitedarea models with nested domains, forced by the ECMWF analysis and with open boundary conditions. In an earlier study (Wu et al. 2009), we followed a similar approach but found that the ECMWF forcing produces a low-level dry bias. Simulating the inner domain only with ECMWF wind boundary forcing but replacing the ECMWF temperatures and humidities with observed values alleviates some of this problem. We test the sensitivity to this forcing assumption in the next section.

The active monsoon period of TWP-ICE had moist westerly flow from ocean to land and extensive, synoptically forced maritime-style convection; simulations of this period are limited by the accuracy of ECMWF winds and the parameterized microphysics, a source of considerable model-to-model variation in the intercomparison of Varble et al. (2011). The monsoon break period was dominated by easterly winds and unstable but drier conditions. Convection during this period was continental, driven by sea breezes and surface fluxes, which are poorly constrained by TWP-ICE data and not used to force the model. Furthermore, systems often propagated into the domain from the east, which the WRF cannot represent. Our simulations of the break period are therefore semi-idealized portrayals of convective development and not directly comparable to observations. Relative humidity $(\mathrm{RH})$ during the active period was $\sim 90 \%$ or higher throughout the troposphere up to the $300-\mathrm{hPa}$ level; during the break period, $\mathrm{RH}$ was $80 \%-85 \%$ in the boundary layer but decreased to $50 \%-$ $60 \%$ in the middle and upper troposphere (see Fig. 1 of $\mathrm{Wu}$ et al. 2009). Wind shear was relatively weak during both periods (see section 2c) but organized convection still developed (Frederick and Schumacher 2008).

The active monsoon simulations are initiated at 1200 UTC 19 January 2006 and run until 1200 UTC 22 January 2006. The monsoon break simulations begin at 1200 UTC 9 February 2006 and run until 1200 UTC 12 February 2006. Both periods are simulated twice, once with the Morrison et al. microphysics and a second time with the Thompson et al. microphysics. Statistics are collected after a 12-h model spinup period. Except when specified otherwise, figures shown are from simulations with the Morrison et al. microphysics; in such cases runs with the Thompson et al. microphysics behaved similarly.

\section{c. Cloud classification scheme}

Figure 3 shows model fields for the active monsoon at 0600 UTC 20 January 2006, close to the time of peak model rainfall. On this day Darwin C-band polarimetric (C-POL) radar indicated a line of convective cells northeast of Darwin, oriented northwest-southeast, with a large stratiform rain region to the south (see Fig. 6 of Varble et al. 2011). The WRF contains a somewhat similar line of convection at this time, but with a much smaller area of surrounding weaker rain rates (Fig. 3, top left). The details of such instantaneous storm structures vary considerably from one model to another (Varble et al. 2011).

Since we have direct information about WRF hydrometeor and dynamical fields, we choose to classify convective systems into distinct elements based on that information rather than using simulated reflectivities. We define the deep convective (CU) region in the WRF as those columns with vertical velocity $w>0$ at all levels from below the $750-\mathrm{hPa}$ level to above the $0^{\circ} \mathrm{C}$ level, and with a total hydrometeor content $q_{h}>0.1 \mathrm{~g} \mathrm{~kg}^{-1}$. Figure 3 (top panels) shows that this definition generally selects areas within or adjacent to the most heavily raining locations. The definition used by $\mathrm{Wu}$ et al. (2009), which required $w>1 \mathrm{~m} \mathrm{~s}^{-1}$ and buoyant air, captures only convective cores and results in a smaller convective area less suited to our current purposes.

We define the stratiform rain (SR) region as grid boxes that do not satisfy the $\mathrm{CU}$ velocity and cloud-base constraints but whose tops lie above the $0^{\circ} \mathrm{C}$ level and whose surface precipitation rates $(P)$ lie in the range $5>$ $P>0.5 \mathrm{~mm} \mathrm{~h}^{-1}$ with $q_{h}>0.1 \mathrm{~g} \mathrm{~kg}^{-1}$. The upper bound is commonly used in convective-stratiform partitioning studies [see, e.g., the discussion in Schumacher and Houze (2003)], while the lower bound is roughly the weakest rain rate detected by satellite rain instruments. This leaves a significant area with $P>5 \mathrm{~mm} \mathrm{~h}^{-1}$ that falls into neither the CU nor SR category. Cross sections through the primary convective region show that although CU locations often have strong updraft speeds and large amounts of condensate, such properties are not exclusive to those locations (middle and bottom panels of Fig. 3); there are numerous grid boxes with similar properties in the upper troposphere, often close to the convective updrafts. Rain radar studies often define a separate "transition" region between the convective and stratiform parts of a cluster with intermediate rain rates (e.g., Atlas et al. 1999) and sometimes a minimum in reflectivity (e.g., Braun and Houze 1994). It is not 


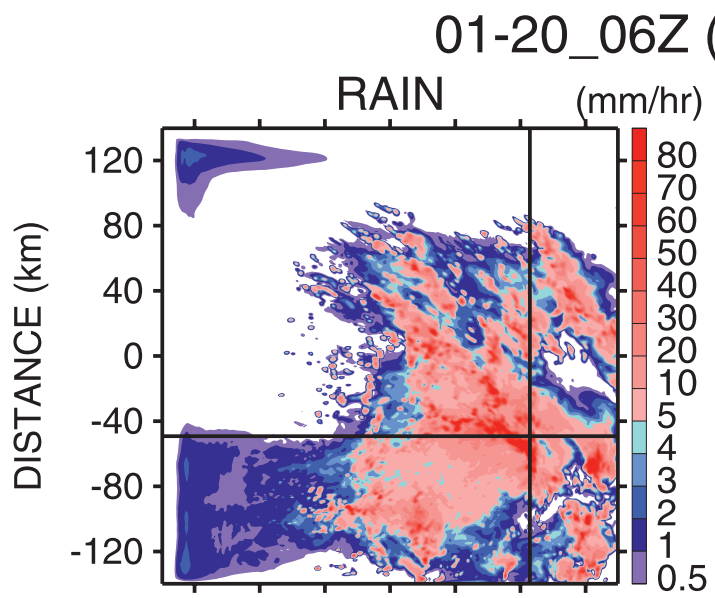

(Morrison)
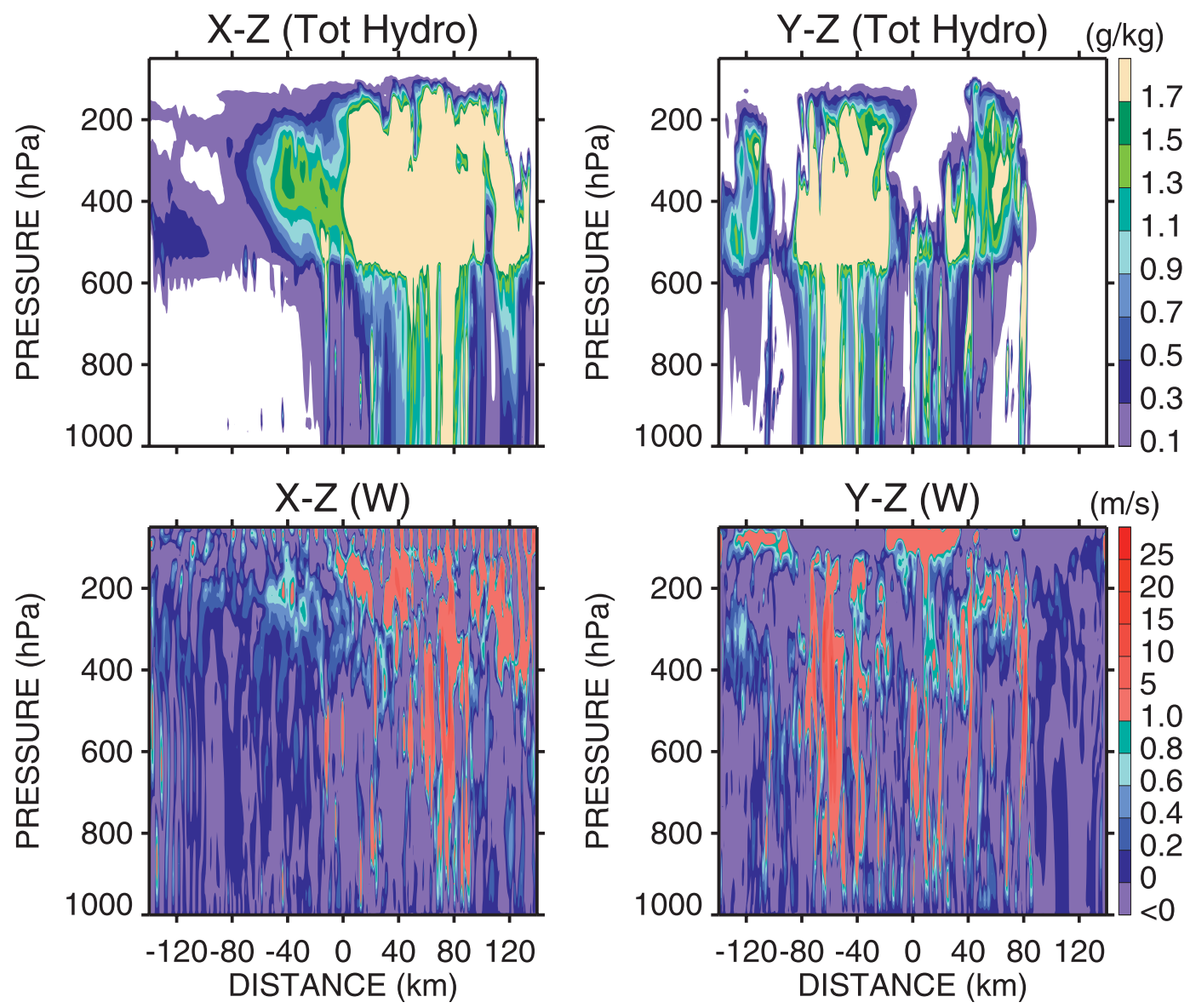

FIG. 3. (top left) Surface rain rate and (top right) area classification (CU, TR, and SR) at 060020 Jan 2006 during the active period. Vertical and horizontal lines indicate the locations of the longitude-altitude (X-Z) and latitudealtitude (Y-Z) cross sections of (middle) hydrometeor mixing ratio and (bottom) vertical velocity.

clear whether such areas should be considered part of either the convective or stratiform region [see the discussion in Schumacher and Houze (2003)], so we opt to define a separate "transition rain" (TR) category, analogous to the SR definition but with $P>5 \mathrm{~mm} \mathrm{~h}^{-1}$. We argue later that properties of the TR region identify

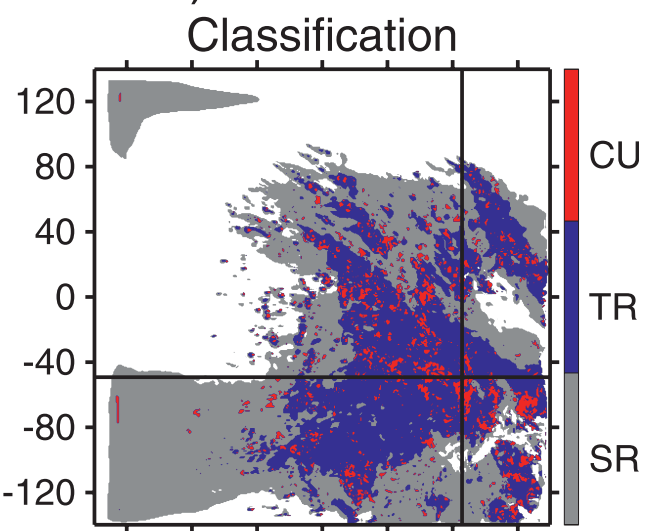

\section{SR}

1

0.9

0.7

0.5

0.3 0.1 
TABLE 1. Percent area covered by CU, TR, and SR during the active monsoon and monsoon break simulations with different microphysics parameterizations. Three numbers reported for the Morrison et al. microphysics case represent the control, no-shear, and nested grid simulations, respectively. Observations (obs) are from Frederick and Schumacher (2008), who do not define a separate TR category.

\begin{tabular}{|c|c|c|c|c|c|c|c|c|c|c|}
\hline \multirow[b]{2}{*}{ Region } & \multicolumn{5}{|c|}{ Active monsoon } & \multicolumn{5}{|c|}{ Monsoon break } \\
\hline & & Morrisor & & Thompson & Obs & & Iorris & & Thompson & Obs \\
\hline $\mathrm{CU}$ & 3.2 & 2.7 & 2.0 & 3.1 & 8.6 & 0.2 & 0.4 & 0.5 & 0.2 & 2.2 \\
\hline TR & 10.9 & 7.2 & 3.8 & 9.5 & & 1.2 & 1.7 & 2.1 & 0.8 & \\
\hline SR & 40.3 & 38.3 & 18.7 & 34.3 & 33.2 & 2.4 & 3.0 & 4.0 & 1.6 & 5.6 \\
\hline Total & 54.4 & 48.2 & 24.5 & 46.9 & 41.8 & 3.8 & 5.1 & 6.6 & 2.6 & 7.8 \\
\hline
\end{tabular}

boxes and adjacent to SR areas. Table 1 shows the area covered by convective and stratiform rain in the model versus those derived from TWP-ICE C-POL radar data (Frederick and Schumacher 2008). Frederick and Schumacher do not define a separate TR region, but their convective-stratiform separation (based on reflectivity patterns) defines high reflectivity regions $\left(\sim 10 \mathrm{~mm} \mathrm{~h}^{-1}\right.$ or higher rain rate) as convective; the most straightforward comparison is thus with the sum of our CU and TR areas. Given that Frederick and Schumacher use a different classification scheme over a longer time and smaller area (the 120-km-radius C-POL field of view) than ours, the agreement between model and data is reasonable. WRF slightly overpredicts the raining area during the active period and underpredicts it during the break period; the active period raining area lies within the range of the CRMs analyzed by Varble et al. (2011). The Morrison et al. microphysics simulates larger TR and SR areas than the Thompson et al. microphysics. This may be due to differences in their particle size distributions. Morrison et al. (2009) use a Marshall-Palmer distribution for rain, with a constant intercept in the single-moment version. Thompson et al. (2008) use a gamma distribution with a variable intercept and slower fall speeds (their Fig. A1) and thus get a smaller area that exceeds our rain thresholds for TR and SR. The WRF SR/(TR+CU) area ratio is somewhat smaller than observed in both periods for both microphysics schemes. For both schemes, however, the raining area is much greater during the active period than the break period, consistent with the wetter active period conditions.

Wind shear is important for the development of convective organization (e.g., Houze 2004; Tao and Moncrieff 2009). During TWP-ICE, however, wind shear was fairly weak (Fig. 4), $\sim 1 \mathrm{~m} \mathrm{~s}^{-1} \mathrm{~km}^{-1}$ or less through the troposphere during the active period when convection was highly organized, and actually greater $\left(\sim 3 \mathrm{~m} \mathrm{~s}^{-1} \mathrm{~km}^{-1}\right)$ in the lowest $3 \mathrm{~km}$ during the break period, when convection was less organized and shorter lived. Convective available potential energy from the Xie et al. (2010) data was moderate (1647 and $2273 \mathrm{~J} \mathrm{~kg}^{-1}$ for the active and break periods, respectively), and the cold pool temperature
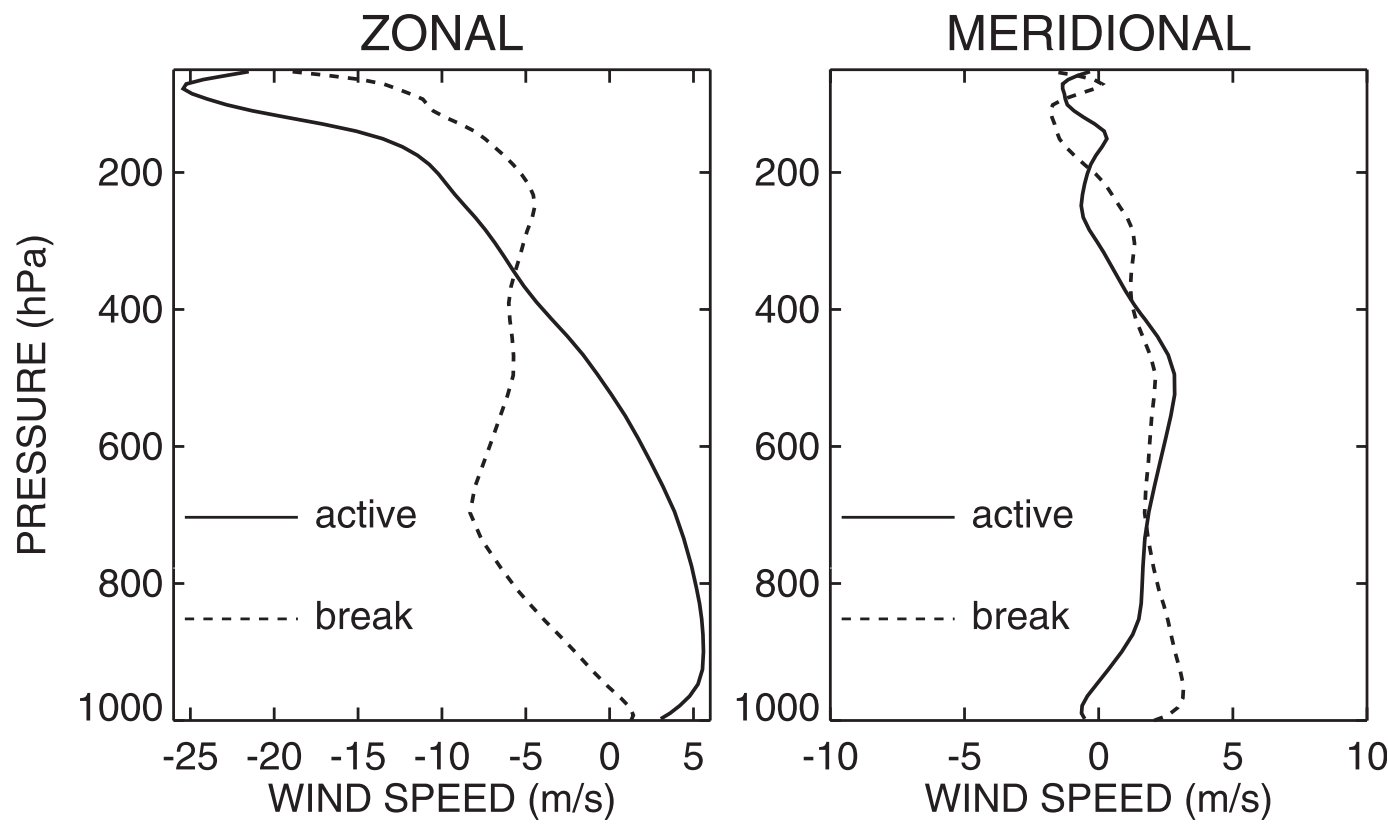

FIG. 4. Domain and time mean (left) zonal and (right) meridional wind profiles for the active and break periods. 


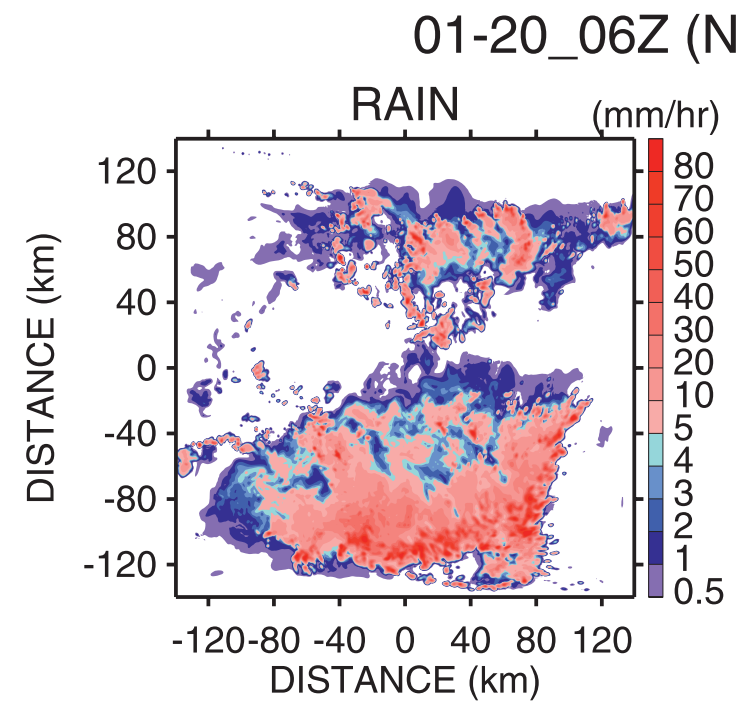

\section{NO-SHEAR)}

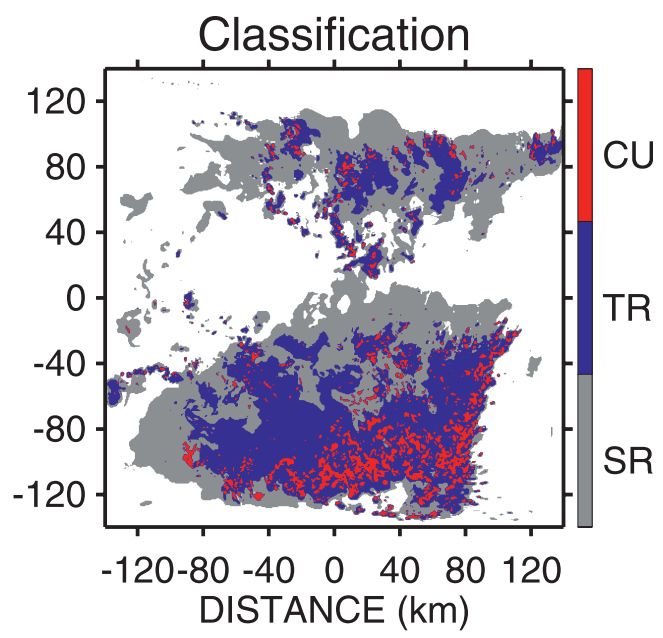

01-20_06Z (NESTED)
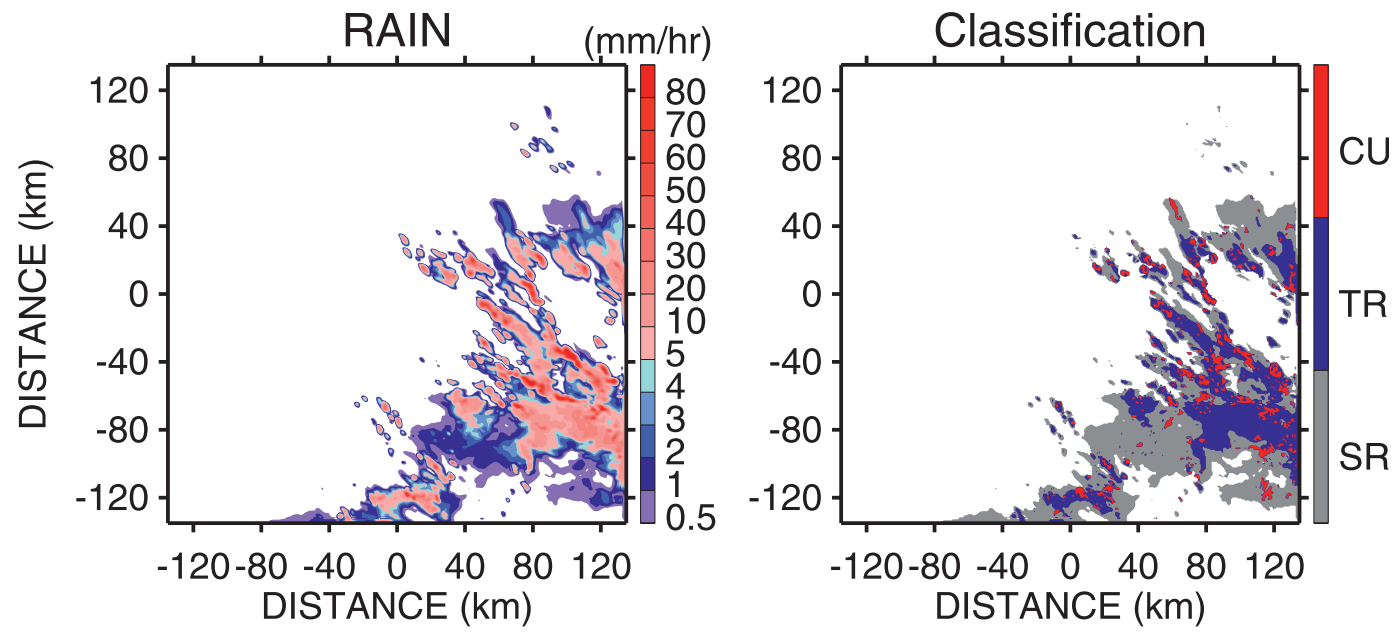

FIG. 5. As in (top) of Fig. 3, but for the (top) no-shear and (bottom) nested active period simulations.

perturbation was $\sim 4 \mathrm{~K}$ (see section 3 ), putting the atmosphere well within the weak shear regime whether this is assessed using a full troposphere convective Richardson number (Tao and Moncrieff 2009) or a local index of low-level buoyant vorticity generation relative to shear at the gust front (Rotunno et al. 1988). Houston and Wilhelmson (2011) have shown that organized, long-lived convection can occur in low shear conditions as long as a sufficiently deep cold pool is produced.

To test whether our results are sensitive to wind shear, we subtracted the domain mean wind profile from the ECMWF boundary forcing at each time step and from the initial condition within the domain and repeated the active and break control run simulations with the Morrison et al. microphysics. The top panels of Fig. 5 are analogous to those of Fig. 3 for the active period "no shear" run. The position and morphology of the convection are somewhat different without shear, but the areal coverage of the convective and stratiform regions (Table 1) hardly changes. Relationships shown later between the convective and stratiform areas are largely unaffected as well for both the active and break periods. We conclude that for the cases we study, active-break humidity differences primarily determine how convection develops.

To test the sensitivity to forcing, we also repeated the control runs using a traditional nested grid approach with three domains. The inner domain is $270 \mathrm{~km} \times$ $270 \mathrm{~km}$; it is surrounded by a $510 \mathrm{~km} \times 510 \mathrm{~km}$ middle domain and a $1560 \mathrm{~km} \times 1560 \mathrm{~km}$ outer domain. The middle domain has a $3-\mathrm{km}$ resolution and no cumulus parameterization. The outer domain has a $15-\mathrm{km}$ resolution and uses the updated Kain-Fritsch cumulus 
parameterization (Kain 2004). All domains are initialized by the ECMWF analysis, and boundary conditions are updated every $6 \mathrm{~h}$ using ECMWF for the outer domain and the simulations from the corresponding outer parent domains for the nested domains. The bottom panels of Fig. 5 show analogs to the top panels of Fig. 3 for the active nested grid run. This simulation removes some raining areas that exist near the western (inflow) boundary in the control simulation. Because of the ECMWF lowlevel dry bias, though, the nested grid run produces less convection and a much smaller SR area (Table 1). The qualitative differences between the active and break period raining areas remain, though. In fact, the smaller active period raining area in the drier nested run relative to the control run reinforces our impression that the area is controlled by the humidity of the environment.

\section{Downdraft cold pools}

Most GCMs parameterize convective downdrafts, which maintain boundary layer quasi-equilibrium by transporting low moist static energy air from the middle troposphere (Emanuel et al. 1994). Historically, cumulus parameterizations have instantaneously mixed downdraft air that enters the boundary layer with ambient air there, which stabilizes the column and suppresses further convection. Previous studies have suggested, however, that cold pools that form from downdraft descent remain distinct for hours. As they spread over time and organize convergence and high moist static energy at the gust front, further convection is promoted rather than suppressed (Zipser 1977; Mapes 2000; Tompkins 2001; Khairoutdinov and Randall 2006).

The TWP-ICE break period is most conducive to exploring cold pools, since convection is more localized and the cold pools are more limited in area and distinct from other locations. Figure 6 shows the evolution of surface rain rate and temperature during one afternoon. The temperature color bar is chosen so that red/blue distinguishes the land and ocean surfaces before precipitation first reaches the surface over the mainland in the southern half of the domain. After the mainland rain begins (0400 UTC), small pockets of cooler surface air can be seen at the rain locations, which expand to become distinct cold pools by 0600 UTC, when the rain rate peaks. The cold pools continue to expand (at a mean rate of $\sim 3-4 \mathrm{~m} \mathrm{~s}^{-1}$ ) as rain weakens at 0800 UTC, eventually covering an area comparable to a climate GCM grid box, until the undisturbed land surface cools in early evening (10 UTC $=7: 30$ p.m. LST) to a temperature similar to the cold pool.

The coastal geography of Darwin is a complicating factor for our simulations, but it has one advantage — cold pools that form over the mainland eventually spread to the adjacent ocean. This allows us to diagnose cold pool recovery separately over land and ocean for the same convective event. The land cold pool is easily identifiable during daytime as areas with temperature $<31^{\circ} \mathrm{C}$ (Fig. 6). The ocean cold pool is more difficult to isolate, since the ocean is cooler than the undisturbed land surface. We find that for the area south of the Tiwi Islands $(y<40 \mathrm{~km})$, and excluding a small area of cooler ocean along the west coast of the mainland $(x<-60 \mathrm{~km})$, a criterion of temperature $<29^{\circ} \mathrm{C}$ satisfactorily identifies the ocean cold pool grid boxes.

The resulting temporal evolution of the cold pools is different over ocean and land (Fig. 7). Cold pools do not reach the ocean surface until shortly after 4:00 p.m. When they do, downward shortwave (SW) and longwave (LW) fluxes decrease and ocean surface air temperatures and humidities in the cold pool locations are $\sim 1.5^{\circ} \mathrm{C}$ colder and $\sim 1 \mathrm{~g} \mathrm{~kg}^{-1}$ drier than elsewhere. This leads to a sharp increase in surface sensible and latent heat fluxes that gradually restore the cold pool air to ambient characteristics over the next $\sim 3 \mathrm{~h}$ while the surface fluxes relax back to pre-cold pool values. This progression resembles that seen by Tompkins (2001).

Over land, cold pool evolution is different. Continental cold pools are first detected at 1:00 p.m.; downward SW and LW fluxes decrease relative to the surroundings, surface air temperature is quickly depressed by $\sim 4 \mathrm{~K}$, and surface humidity increases by $\sim 2 \mathrm{~g} \mathrm{~kg}^{-1}$. Unlike the ocean case, however, the low thermal inertia land surface cools. Surface sensible heat flux thus rapidly decreases and is not able to restore the surface air to pre-cold pool conditions. Meanwhile the latent heat flux gradually decreases as well. The net result is that the initial surface air temperature and humidity anomalies persist until early evening, by which time the undisturbed land surface cools diurnally to a temperature similar to that of the cold pool and the cold pool/non-cold pool distinction disappears (the cold pool does remain wetter than its surroundings through the night). Surface air temperature data during the break period at the Howard Springs station show similar behavior (Fig. 8) in response to the passage of a storm [see Figs. 11 c,d of Frederick and Schumacher (2008)] at $\sim 2200$ LST (1230 UTC) 10 February, with an immediate cooling of $\sim 3^{\circ}-4^{\circ} \mathrm{C}$ and then nearly constant temperature until 0600 LST 11 February, when the normal downward diurnal temperature progression resumes.

Vertical velocity at the time of peak rainfall at $600 \mathrm{~m}$ and 2-km altitude, the latter close to the mean cloud base, is shown in Fig. 9. Strong updrafts $\left(>1 \mathrm{~m} \mathrm{~s}^{-1}\right)$ are found almost exclusively in curved arcs surrounding locations of current and previous heavy rain (Fig. 6), suggesting an origin at cold pool gust fronts. Strong downdrafts exist just 

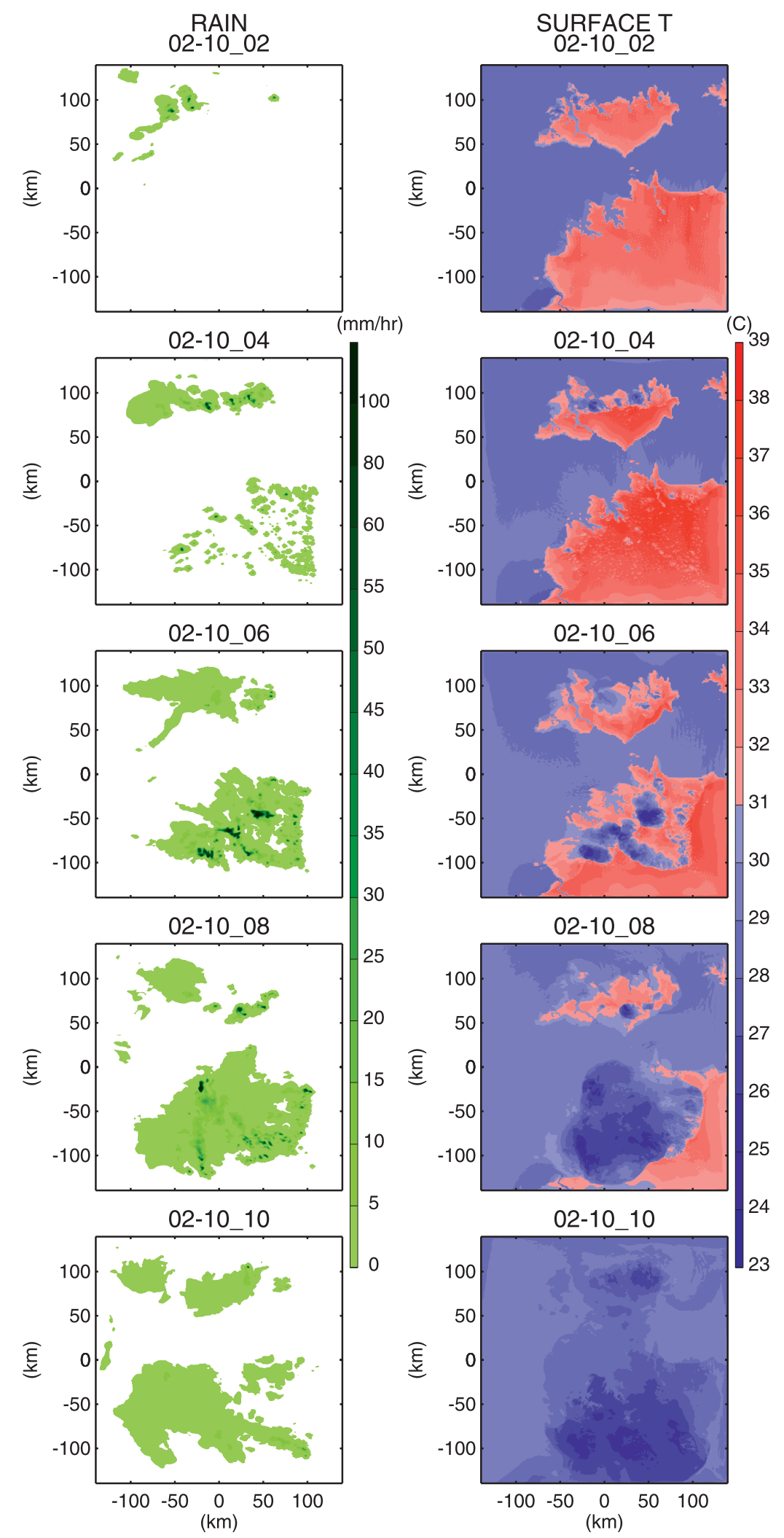

FIG. 6. Surface (left) precipitation rate and (right) air temperature at 2-h intervals during the break period simulation. 

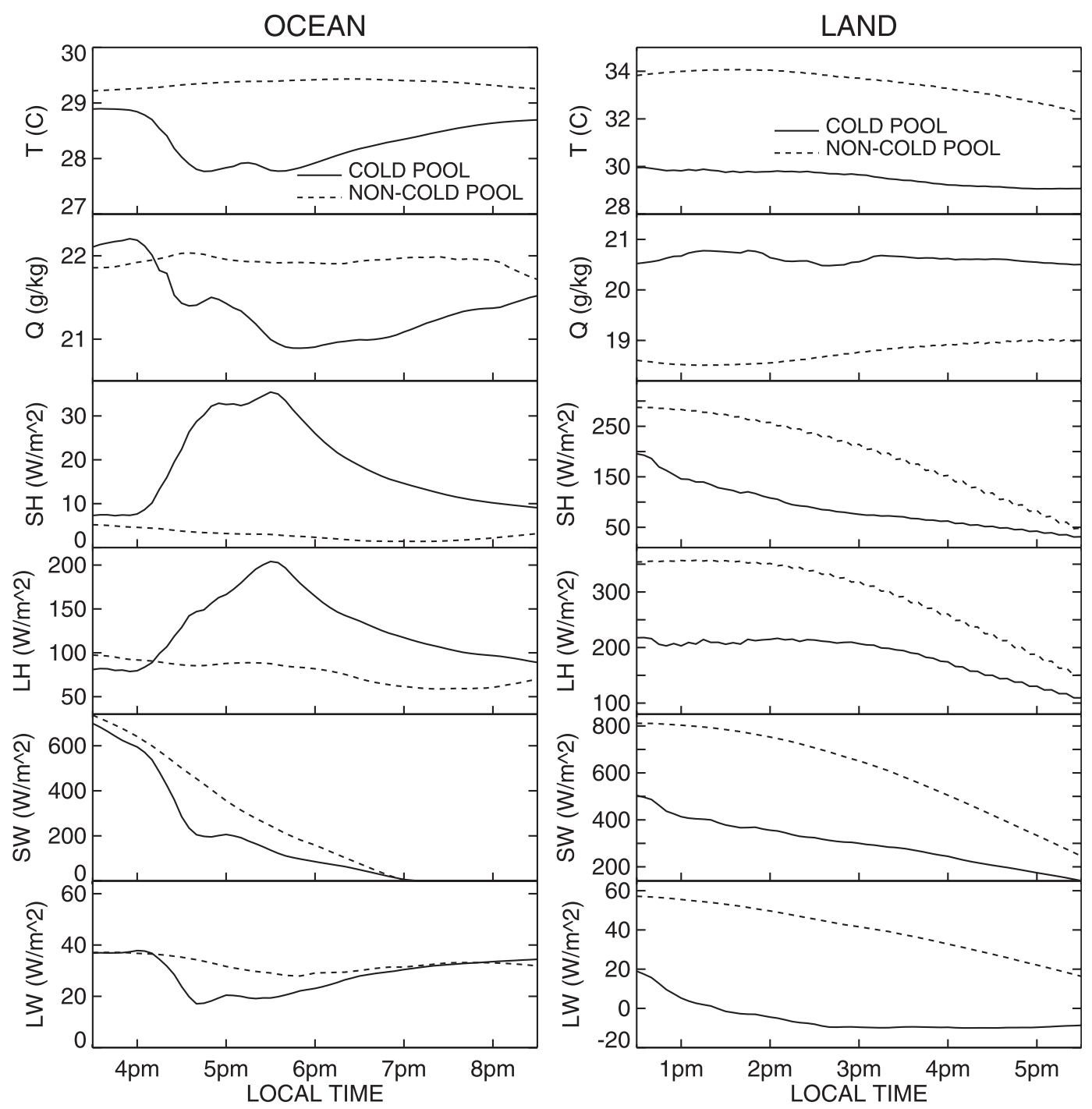

FIG. 7. Temporal evolution of (first row) mean cold pool (solid) and non-cold pool (dashed) temperature, (second row) specific humidity, (third row) surface sensible heat flux, (fourth row) surface latent heat flux, (fifth row) downwelling SW flux, (sixth row) and downwelling LW flux for the cold pools over (left) ocean and (right) land.

inside these arcs, marking the presumed source of the cold pools. The spatial scale of strong upward motions at $600 \mathrm{~m}$ altitude is several kilometers, somewhat larger than the typical turbulent eddies that arise over land earlier in the day before cold pool onset (not shown). At $2 \mathrm{~km}$ altitude, the gust front eddies have expanded in scale to $\sim 10 \mathrm{~km}$, with upward motions of 4-5 $\mathrm{m} \mathrm{s}^{-1}$ in some locations.

\section{Maintenance of the stratiform rain region}

\section{a. Characteristics of the $C U, T R$, and SR regions}

Figure 10 shows the evolution of temperature anomalies in the TR (upper) and SR (lower) regions for the active period control runs. TR upper-troposphere air is buoyant by up to $0.5^{\circ}-1^{\circ} \mathrm{C}$, suggesting that it originated via detrainment from buoyant CU updrafts. Sharp transitions to cool anomalies are sometimes present near the $0^{\circ} \mathrm{C}$ level $(545 \mathrm{hPa})$, indicating melting of falling ice, and more so for the run with the Morrison et al. microphysics. The major instances of such cooling ( $\sim 0600$ UTC each day) are accompanied by cool anomalies through part or all of the lower troposphere, with air several degrees colder than average near the surface. This suggests that the TR region is where convective downdrafts and cold pools are initiated.

The SR region is somewhat different. Upper-troposphere temperature anomalies are no more than several tenths of a degree and are occasionally cool rather than warm, that is, SR is close to neutrally buoyant. Melting level negative anomalies are small but consistent in time. Lower 


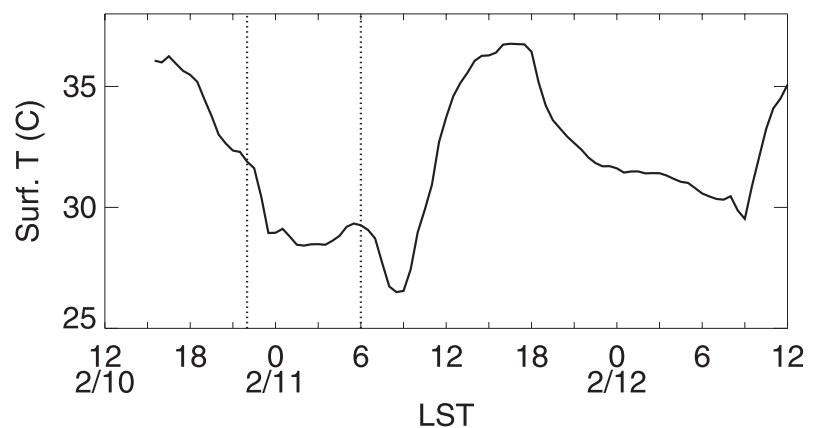

FIG. 8. Observed surface temperature time series at Howard Springs station ( $\sim 25 \mathrm{~km}$ east of Darwin) during the TWP-ICE monsoon break period, showing the effect of a cold pool associated with passage of a storm at 2200 LST 10 Feb 2006. Dotted vertical lines show the onset and termination of the cold pool event at the station.

troposphere anomalies are similarly small and surface cold pools are absent, with one exception.

Figure 11 shows probability distributions of vertical velocity for the active monsoon. CU velocities (left panels) are several meters per second, similar to those observed in oceanic (Zipser and Lutz 1994) and Darwin active monsoon (May and Rajopadhyaya 1999) convection [the updraft speed probability distribution function (pdf) differs from that in $\mathrm{Wu}$ et al. (2009), in part because that paper used an earlier version of ARW-WRF with different parameterizations, but primarily because here we use a more liberal definition of convective updraft grid boxes that does not isolate convective cores]. CU pdfs below the melting level are similar in the runs with the two different microphysics parameterizations but differ above, especially the 99th percentile. Strong updrafts in the Morrison et al. (2009) run strengthen from the melting level to $\sim 400 \mathrm{hPa}$ and then weaken above, while those in the Thompson et al. (2008) run slightly weaken above the melting level and then strengthen from $\sim 400$ to $200 \mathrm{hPa}$. A possible reason is the differing treatment of graupel in the two schemes. Morrison et al. use fixed hydrometeor mixing ratio thresholds for forming graupel and make graupel from collisions between rain and snow, rain and cloud ice, and snow and cloud liquid. Thompson et al. form graupel only from snowcloud liquid collisions when riming growth is faster than depositional growth, consistent with their desire to maintain supercooled liquid water. Thus, ice formation (and latent heat release, which increases buoyancy) in the Thompson et al. run occurs primarily far below $0^{\circ} \mathrm{C}$, where primary ice nucleation and heterogeneous or homogeneous freezing occur, whereas the greater graupel formation in the Morrison et al. run, which occurs primarily at warmer temperatures, accelerates parcels within a few kilometers above the melting level.

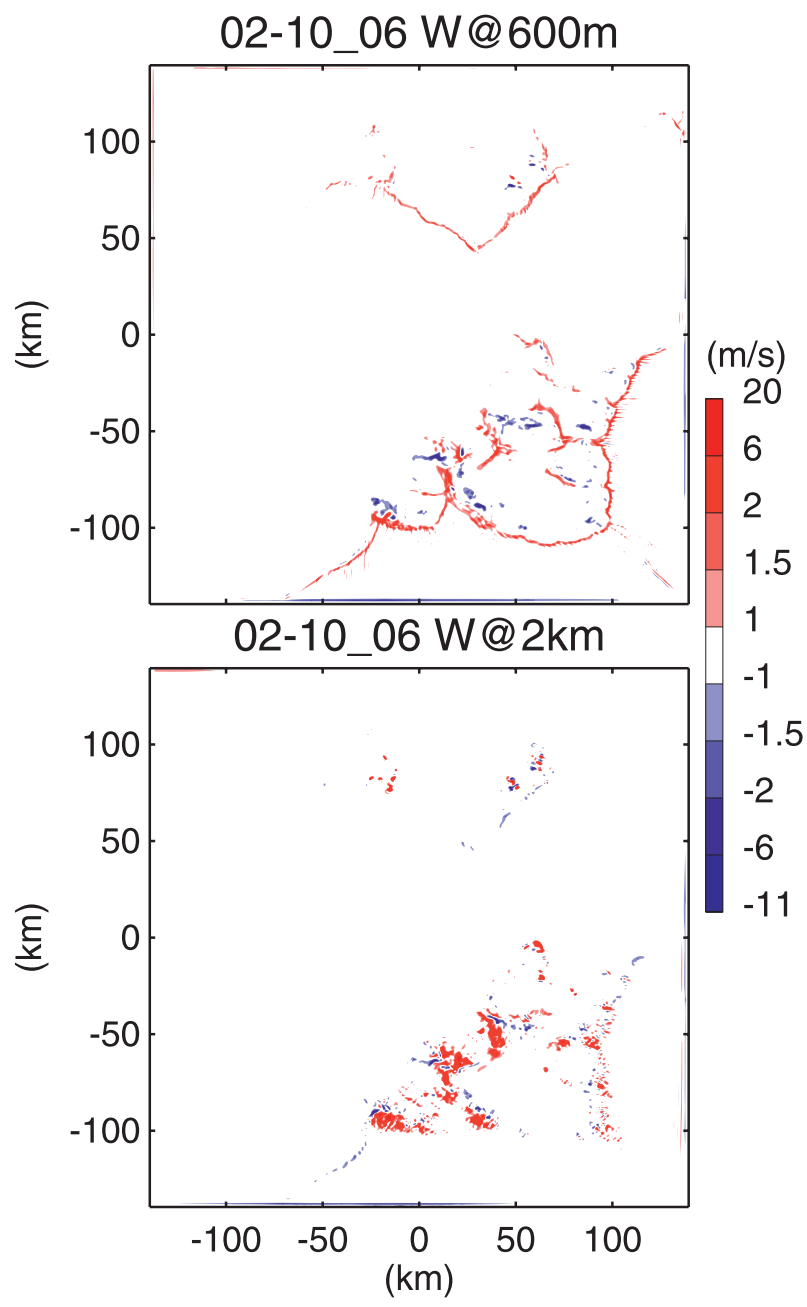

FIG. 9. Simulated 10-min average vertical velocity field at (top) $600 \mathrm{~m}$ and (bottom) 2-km altitude at $060010 \mathrm{Feb} 2006$.

SR vertical velocities (Fig. 11, right panels) are both positive and negative at all altitudes, but the mean is positive (negative) above (below) the melting level, as expected. Mesoscale updraft velocities are tens of centimeters per second and mesoscale downdrafts are slightly weaker, consistent with field experiments (Houze 1989). The SR vertical velocity distributions are less sensitive to the choice of microphysics than those in the $\mathrm{CU}$ region. TR updraft speeds are not surprisingly intermediate between those of the CU and SR regions. The mean TR updraft speed in the upper troposphere is only slightly stronger than its SR counterpart, but the upper $10 \%$ of velocities are several meters per second, again suggesting that the TR region contains detrained $\mathrm{CU}$ air.

Vertical velocities during the break period (not shown) are stronger, peaking (99th percentile) at $25-30 \mathrm{~m} \mathrm{~s}^{-1}$ near $200 \mathrm{hPa}$ in the $\mathrm{CU}$ region for both microphysics schemes. In general, the strongest updrafts in all three 


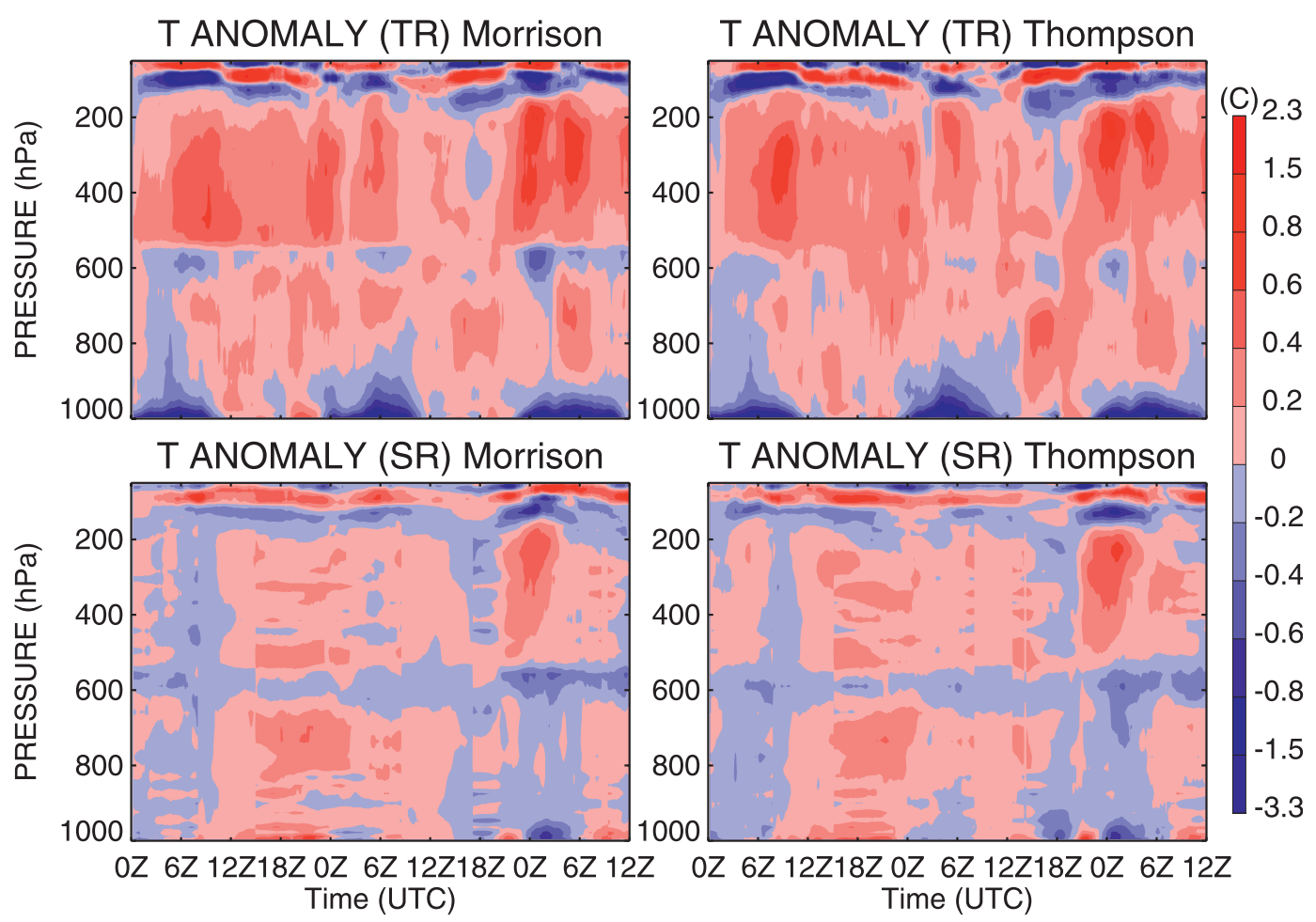

FIG. 10. Vertical profiles of mean (top) TR and (bottom) SR region temperature anomalies relative to the domain mean for the active monsoon period simulations with the (left) Morrison et al. (2009) and (right) Thompson et al. (2008) microphysics.

regions are somewhat stronger in the Thompson et al. (2008) simulation, but otherwise the vertical velocities are less sensitive to the choice of microphysics.

The vertical profiles of hydrometeor species for the active monsoon are shown in Fig. 12. Convective rain profiles are almost identical for the two microphysics schemes, peaking at $0.9 \mathrm{~g} \mathrm{~kg}^{-1}$ at $\sim 700 \mathrm{hPa}$, decreasing to zero at $\sim 450 \mathrm{hPa}$, and with a mixing ratio of $0.6 \mathrm{~g} \mathrm{~kg}^{-1}$ at the surface. Otherwise, the effect of different microphysics is large. The most striking difference is the large amount of snow produced by the Thompson et al. microphysics scheme relative to the Morrison et al. (2009) scheme. This was also noted by Wu and Petty (2010) for a different climate regime (polar lows). They attribute the difference to the assumed size distributions. The single-moment Morrison et al. scheme assumes a MarshallPalmer distribution for snow with a constant intercept. Thompson et al. use the sum of a Marshall-Palmer distribution and a gamma distribution to simulate the "superexponential" number concentration of small particles reported in some observations; this implies slower fall speeds overall and thus a greater buildup of snow via deposition. Cloud ice is almost nonexistent in the Thompson et al. run relative to the Morrison et al. run, but this may be something of an artifact, given that the superexponential size distribution of snow used by Thompson et al. includes sizes usually categorized as cloud ice.

As noted earlier, Thompson et al. (2008) suppress graupel formation when depositional growth is rapid, so the simulation with this microphysics contains only a modest amount of graupel in the CU region, less in the TR region, and almost none in the SR region. This is consistent with the greater fall speed of graupel relative to other ice particles and the weakening of updraft speed from the CU to TR to SR region. It is qualitatively realistic compared to observations of African squall lines, which show some graupel adjacent to convection but little in the far-removed stratiform area (Bouniol et al. 2010; Cetrone and Houze 2011). The Morrison et al. (2009) run, however, produces apparently excessive graupel, with concentrations comparable to snow in the CU and TR regions and nonnegligible even in the SR region. Overestimation of graupel is a chronic problem for many CRMs (Varble et al. 2011). The suppression of riming in the Thompson et al. scheme naturally has the opposite effect on cloud liquid water: peak cloud liquid mixing ratios near the melting level are greater in this simulation than in the Morrison et al. run.

Hydrometeor profiles during the break period (not shown) are similar in most respects but differ from those 
MORRISON
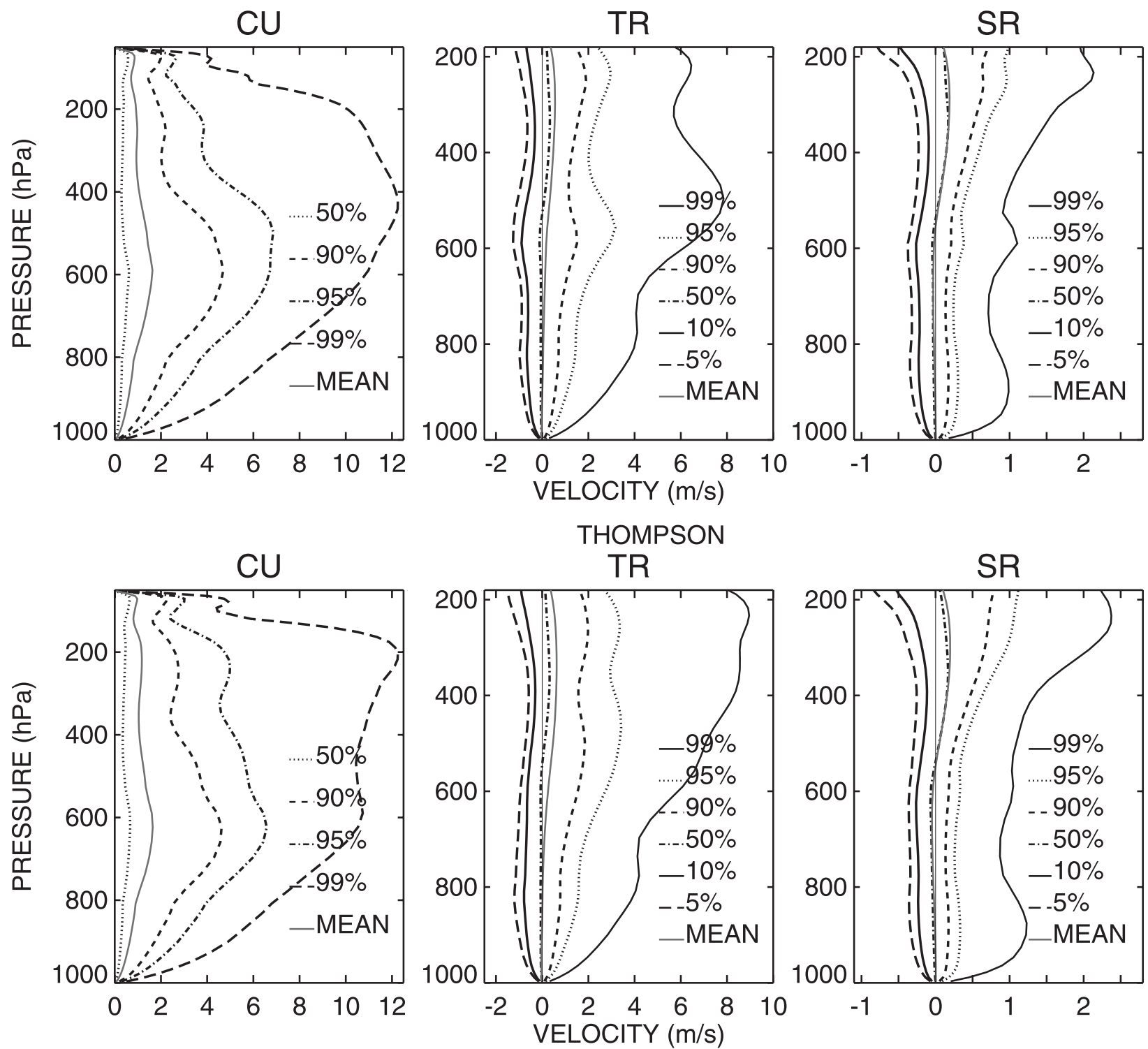

FIG. 11. Vertical velocity distributions (percentiles) vs pressure for the (left) CU, (middle) TR, and (right) SR regions in the active period simulations with the (top) Morrison et al. (2009) and (bottom) Thompson et al. (2008) microphysics.

for the active period in several ways that reflect the stronger convection during the break period and exaggerate differences between the microphysics schemes. Thompson et al., while producing 2-3 times more graupel in the CU region during the break period than in the active period, is still dominated by snow at upper levels, whereas the Morrison et al. break period run actually has much more graupel than snow in the CU and TR regions, and comparable graupel and snow in the SR region. Rain water peaks during the break period at $\sim 600 \mathrm{hPa}$ with a mixing ratio of $\sim 2 \mathrm{~g} \mathrm{~kg}^{-1}$ for both microphysics schemes.

\section{b. Relationships between TR/SR properties, the environment, and parent convection}

The extent to which convection organizes into mesoscale clusters with long lifetimes depends on environmental factors, such as humidity and wind shear, that promote "sustainability"- the ability of convection to regenerate and for mesoscale dynamics to persist (Yuter and Houze 1998; Schumacher and Houze 2006). Differences between the TWP-ICE active and break periods suggest differences in sustainability. The much larger SR area during the active period (Table 1) is consistent 
MORRISON
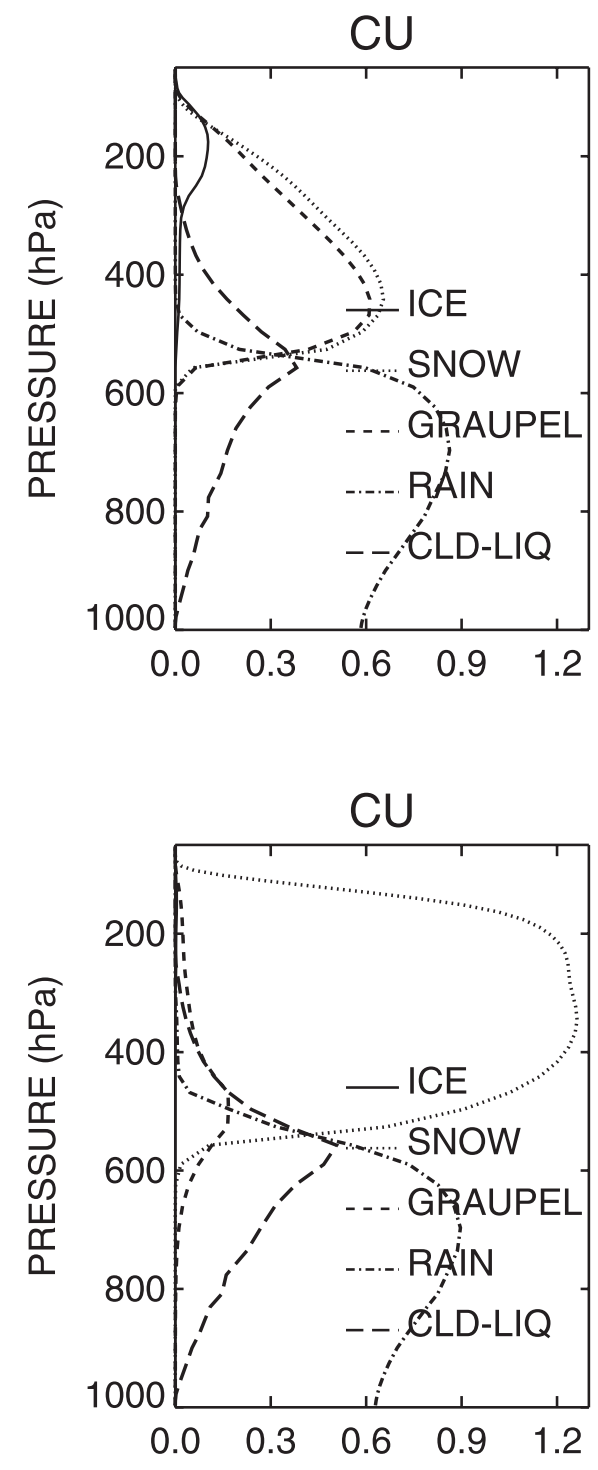
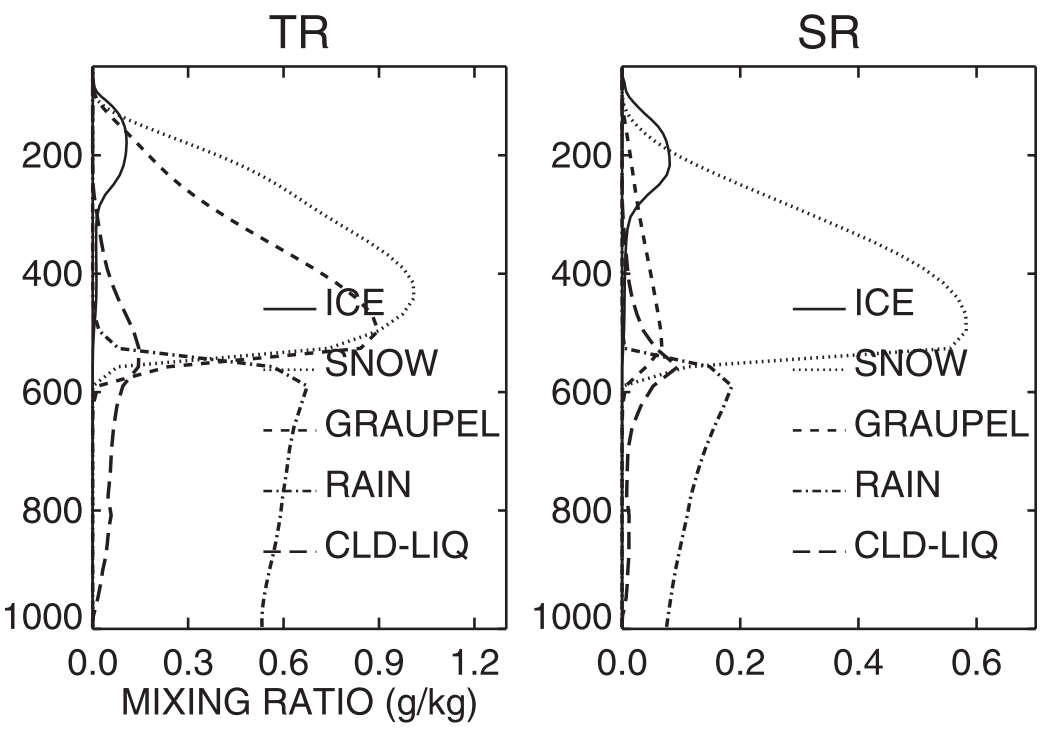

THOMPSON
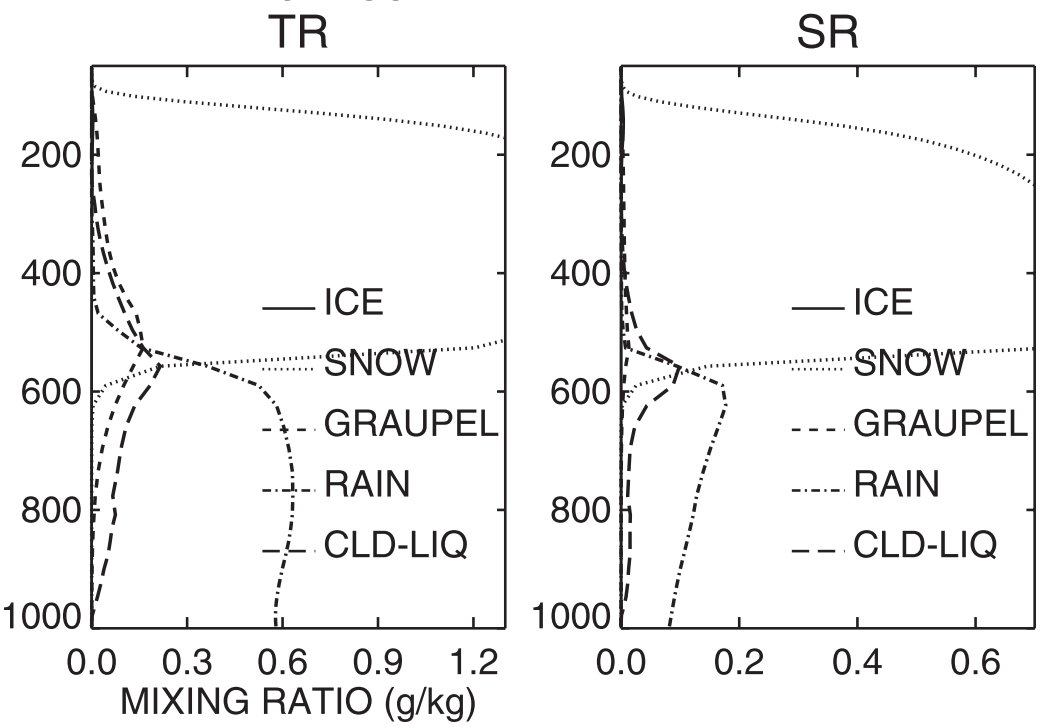

FIG. 12. As in Fig. 11, but for mean profiles of the mixing ratio of different hydrometeor types.

with an environmental humidity control on organization. During the active monsoon, large-scale upward motion creates a positive moisture tendency (Xie et al. 2010) that keeps RH high and sustains convection. During the break period, however, there is little lowlevel moisture tendency, so convection is only maintained by surface fluxes. Cold pools initially trigger new convection (Fig. 6) but surface fluxes decrease over land, so as the cold pool spreads and the undisturbed environment cools diurnally, convection ceases.

A separate question is whether upper-level humidity influences the evolution of the stratiform region once it forms. Figure 13 (top panels) shows lag correlations between 600- and 200-hPa domain mean $\mathrm{RH}$ and the TR/SR area for the active period. The TR area is uncorrelated or weakly negatively correlated with RH, consistent with control by detrainment, not the environment. The SR area is moderately correlated with RH at zero lag but less so at longer lags; the peak correlation is higher (0.9) in the no-shear simulation and lower (0.4) in the nested grid run. Neither the TR nor SR area is significantly correlated with RH during the break period (not shown). Correlations with 600-200-hPa wind shear are negligible during the break period (not shown) but statistically significant during the active period (Fig. 13, bottom panels) at lags of 2-3 h (Morrison et al. microphysics) 

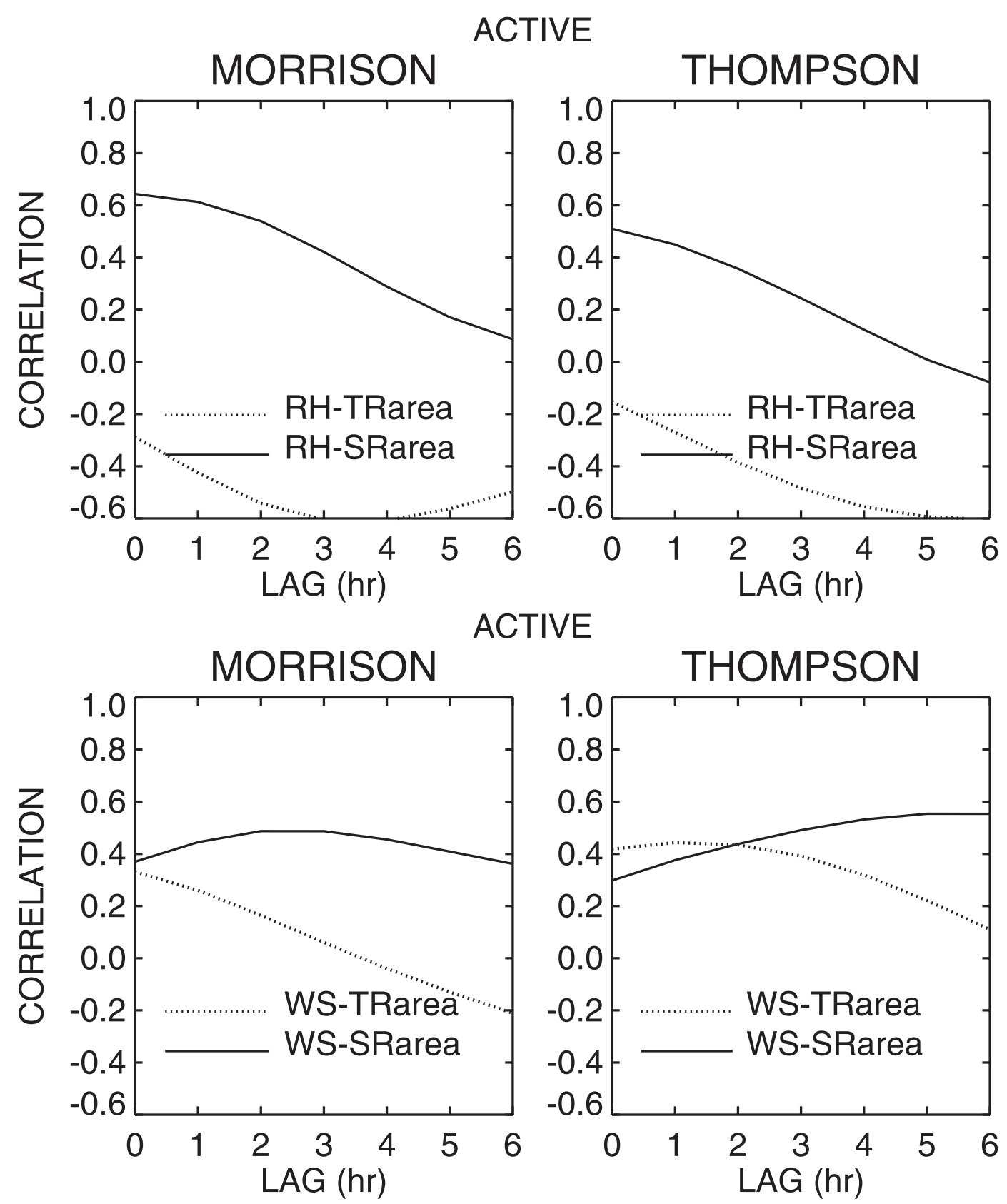

FIG. 13. Lag correlation (top) between 600- and 200-hPa mean RH and the TR or SR area, and (bottom) between 600- and 200-hPa mean vertical shear of horizontal wind and the TR or SR area in the active period simulations with the (left) Morrison et al. and (right) Thompson et al. microphysics. A correlation of 0.27 is significant at the $95 \%$ level.

or 5-6 h (Thompson et al. microphysics). However, the correlation with shear is not robust; it changes sign in the nested grid run.

The immediate question for a parameterization, however, is, given deep convection, how should a stratiform rain region and anvil develop from it? A central question motivating TWP-ICE was whether properties of stratiform clouds accompanying convection are related to the convection itself (mass flux, area, updraft speed, hydrometeor content). Cumulus mass flux (defined as the mean upward vertical velocity from the surface to $600 \mathrm{mb}$ in the CU columns times the fractional CU area) is the best predictor of the TR and SR areas in our simulations (and robust to shear and the forcing method), but in different ways at different times (Fig. 14). The TR area is highly correlated with cumulus mass flux for both the active 
ACTIVE
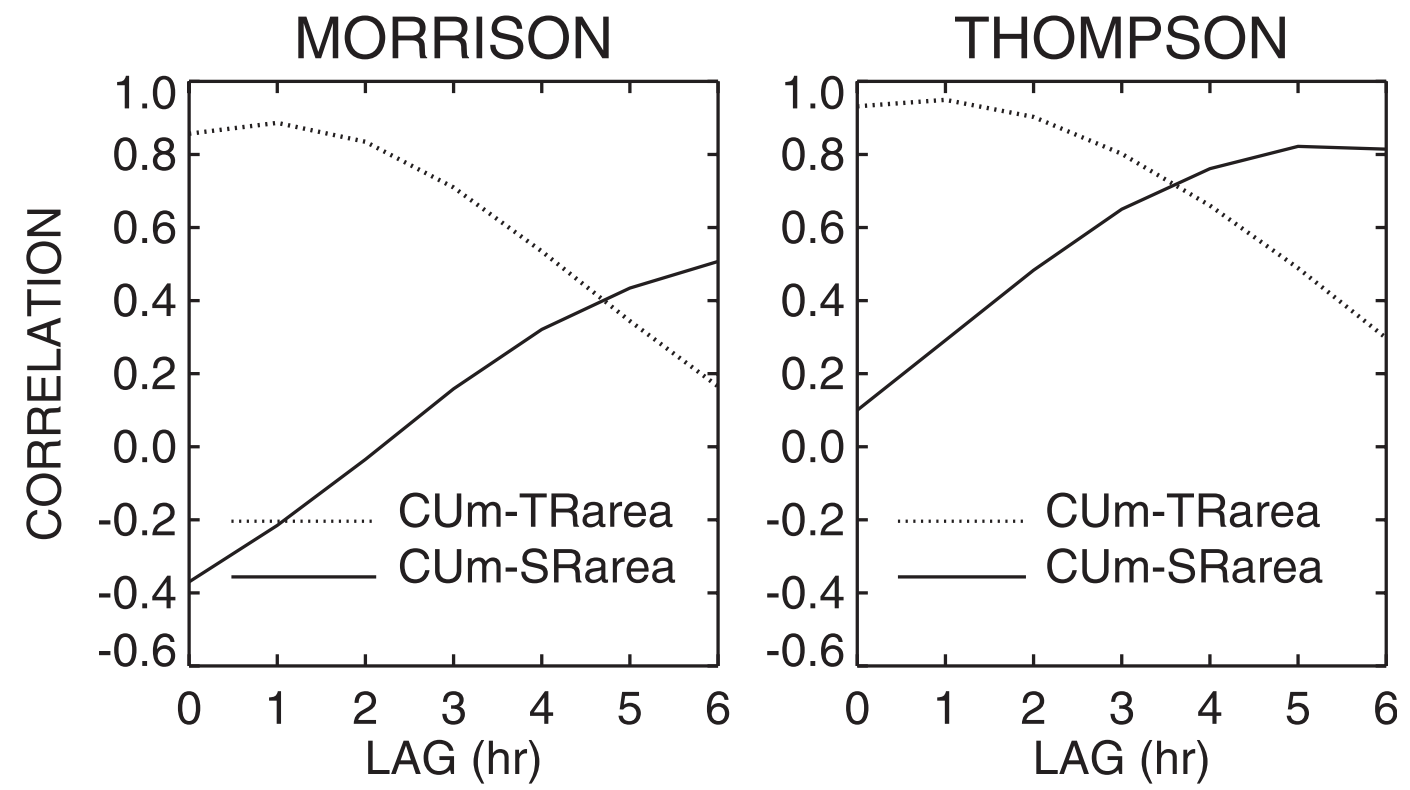

\section{BREAK}
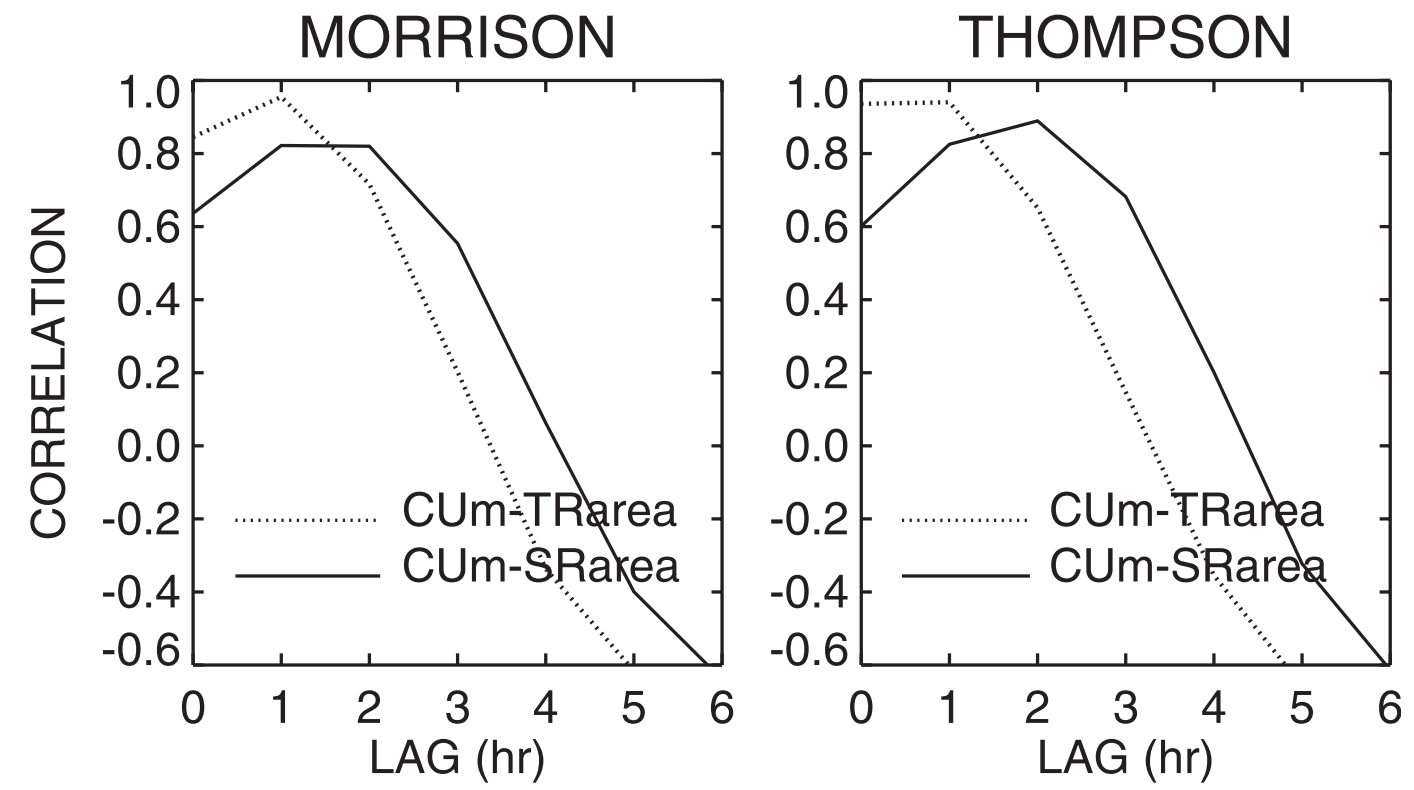

FIG. 14. As in Fig. 13, but for correlations between the cumulus mass flux and the TR or SR area for the (top) active and (bottom) break periods with both microphysics schemes. For the break period, a correlation of $0.31-0.44$ (increasing with lag) is significant at the $95 \%$ level.

and break periods and for both microphysics schemes at a lag of $0-1 \mathrm{~h}$ and decreases sharply thereafter, again consistent with a detrainment source. The SR area during the break period is also highly correlated with cumulus mass flux but with a 1-2-h lag and also decreasing sharply for longer lags, suggesting that in the drier, less sustainable break period environment, the stratiform rain region is simply the onset of the decaying stage of the cluster as convection and detrainment terminatesimilar to the way most GCMs currently treat convection, with no mesoscale in situ source of upward motion and little stratiform heating (e.g., Fig. 2). During the active period, though, the SR area is moderately to highly correlated with the cumulus mass flux only at long lags (5-6 h or more), suggesting that detrained air serves as a trigger that provides ice crystals to the humid environment, 
which then grow by deposition as they sediment, releasing latent heat and eventually generating their own mesoscale updraft, which maintains the stratiform rain for hours.

Combining Figs. 13 and 14, the following tentative story emerges. A humid upper troposphere is important at the outset to allow convection to fully deepen and to provide a nurturing environment for detrained ice crystals. Given this, full in situ development of a mesoscale updraft requires considerable time yet depends for its initiation on ice detrained hours earlier. Note that the microphysics matters: The SR area responds to cumulus mass flux more quickly and strongly with the Thompson et al. microphysics, perhaps since its glaciation is more restricted to higher colder altitudes, where ice can more efficiently grow by deposition.

TR and CU hydrometeor water content are almost perfectly correlated at $0-1-\mathrm{h}$ lag for both the active and break periods and both microphysics schemes and less so at longer lags (not shown), consistent with our previous inferences about this region. SR hydrometeor content behaves similarly during the break period but has lower peak correlations during the active period, especially with the Morrison et al. microphysics, consistent with an important role for in situ ice formation then. The highest correlations for SR hydrometeor content are with cumulus mass flux at $0-1-\mathrm{h}$ lag and cumulus updraft speed at lags of 2-3 h (Fig. 15). Again, these correlations are higher with the Thompson et al. microphysics, perhaps because of its slower ice fall speeds. Updraft speeds in both regions are generally highly correlated with both cumulus updraft speed and cumulus mass flux at 0-1-h lag (not shown), slightly more so for the TR region than the SR region during the active period, although the correlations are noticeably lower for the Thompson et al. break period run.

\section{Discussion}

WRF simulations of different TWP-ICE periods indicate that it is possible for tropical convection to organize on the mesoscale even in weak wind shear environments but that the degree of organization and the area covered by the mesoscale cluster are sensitive to the environmental humidity. Details of the simulations within the domain are sensitive to the microphysics parameterization employed and to the way in which the model is forced, but most of the aggregate properties of the clusters are fairly robust. We therefore feel that it can serve as a useful way to constrain thinking about future parameterization development for GCMs.

The behavior we diagnose (e.g., Figs. 6, 9, and 14) illustrates the parameterization challenge of convective organization. The convective system life cycle of many hours cannot be diagnosed from current large-scale conditions, as cumulus parameterizations currently assume-memory must be added. A successful parameterization of organization must capture three stages of cluster evolution (Futyan and Del Genio 2007): 1) A developing stage in which rain begins, convection deepens, and cluster area grows; 2) a mature stage in which the cluster is at its maximum depth but is still expanding in area, and during which rain rates peak; 3 ) a dissipating stage in which the depth, area, and rain rate decrease, convection weakens and then terminates, and only stratiform rain remnants remain. Stage 1 depends on cold pool formation, its effect on convective triggering and entrainment, and anvil initiation by detrainment. Stage 2 is controlled by the factors that sustain convection plus the physics of the mesoscale updraft and downdraft. Stage 3 depends on the factors that first terminate convection and then terminate stratiform rain.

Several parameterizations of cold pools and their effect on subsequent convection have already been proposed, both detailed (Qian et al. 1998; Grandpeix and Lafore 2010) and simple (Mapes and Neale 2011). A GCM really only needs to know two things about cold pools: areal extent and the temporal evolution of the contrast between cold pool properties and the undisturbed environment. To a first approximation, the cold pool area must increase at the rate at which downdraft air is injected into the boundary layer, since cold pool depth does not vary greatly with time in our simulations (Fig. 10, bottom panels) and in detailed parameterizations (Grandpeix et al. 2010). The WRF simulations also suggest that cold pool evolution can be treated simply in GCMs, using a simple forcing-damping model of cold pool-environment contrast over ocean and constant cold pool temperature and humidity over land (Fig. 7).

Accounting for cold pools in cumulus parameterizations would extend convection lifetime simply by preserving ambient unstable conditions in the remainder of the grid box, but the fact that secondary convection is produced primarily at the cold pool boundary (Fig. 6) indicates that processes specific to the gust front make it easier to trigger deep convection. Most popular is the idea that convergence at the gust front organizes upward motion on larger scales than that of normal turbulence, thus creating larger air parcels that entrain less (Kuang and Bretherton 2006; Khairoutdinov and Randall 2006). Others suggest that enhanced lifting due to convergence at the gust front is the key process, either because it helps parcels reach the level of free convection (Grandpeix and Lafore 2010; Houston and Wilhelmson 2011) or because it weakens entrainment by reducing the time spent per unit distance over which the parcels rise (Del Genio and 
ACTIVE

MORRISON

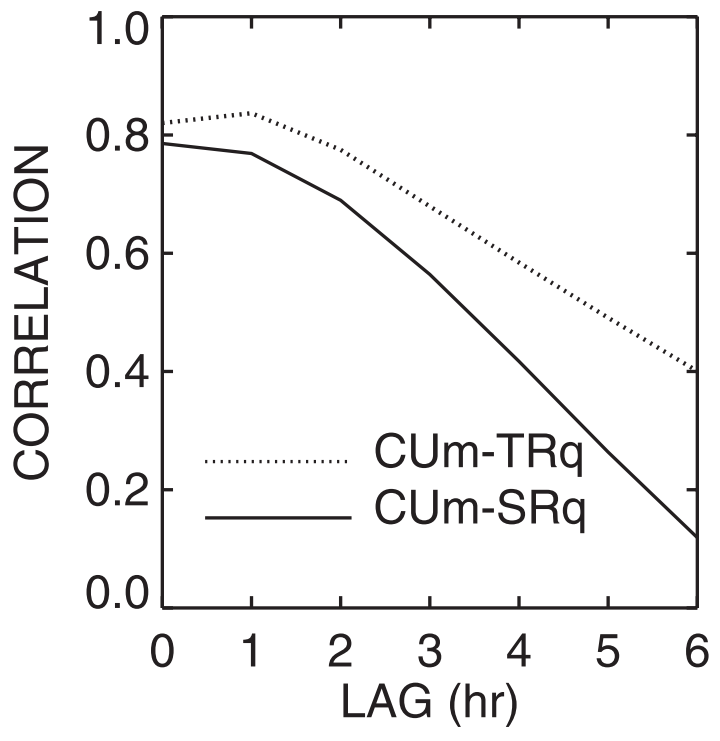

THOMPSON

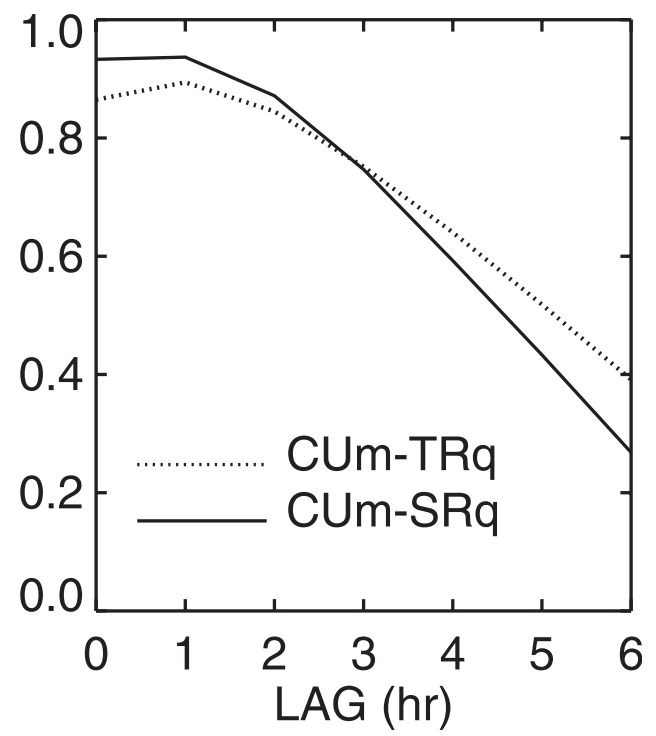

ACTIVE

MORRISON

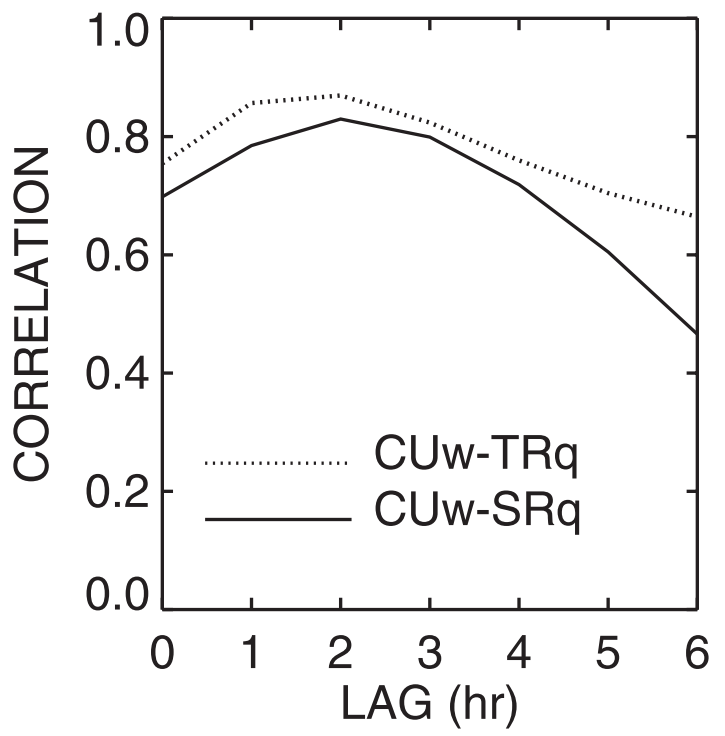

THOMPSON

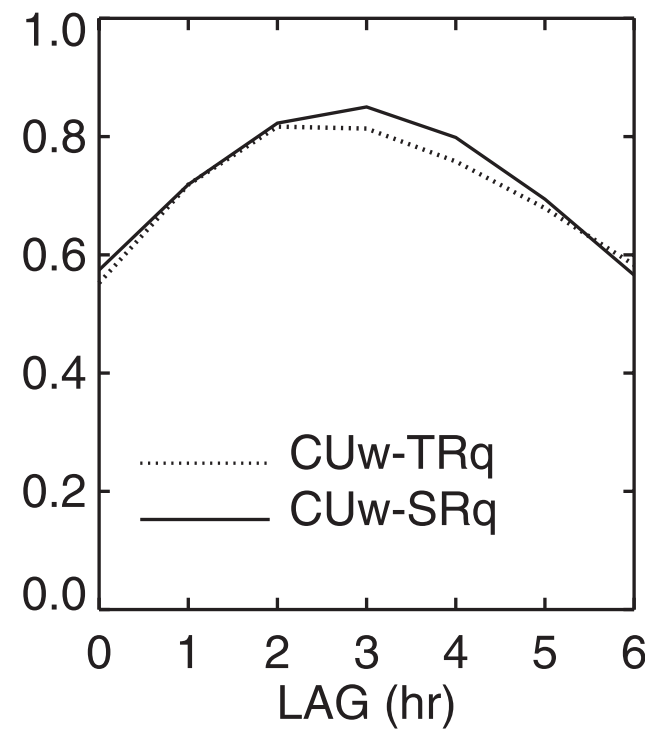

FIG. 15. As in Fig. 13, but for correlations (top) between the cumulus mass flux and the TR or SR hydrometeor mixing ratio and (bottom) between the cumulus updraft speed and the TR or SR hydrometeor mixing ratio during the active period.

Wu 2010). All of these effects are present in our simulations (Fig. 9), but it is not clear which is most important. Piriou et al. (2007), for example, propose an entrainment scheme with memory using a prognostic equation for the probability of undiluted updrafts at a given level that increases with rain evaporation, which accomplishes cold pool enhancement of convection in an abstract way without invoking a particular mechanism.
Another possible reason for secondary convection to be less affected by entrainment is that the updrafts entrain more humid air than other parts of the environment due to preconditioning by detrainment from earliergeneration plumes (Mapes and Neale 2011). Figure 16 shows the cloud classification and the 600-hPa RH field during our active and break WRF simulations. During the nearly saturated active period (top panels), the air 

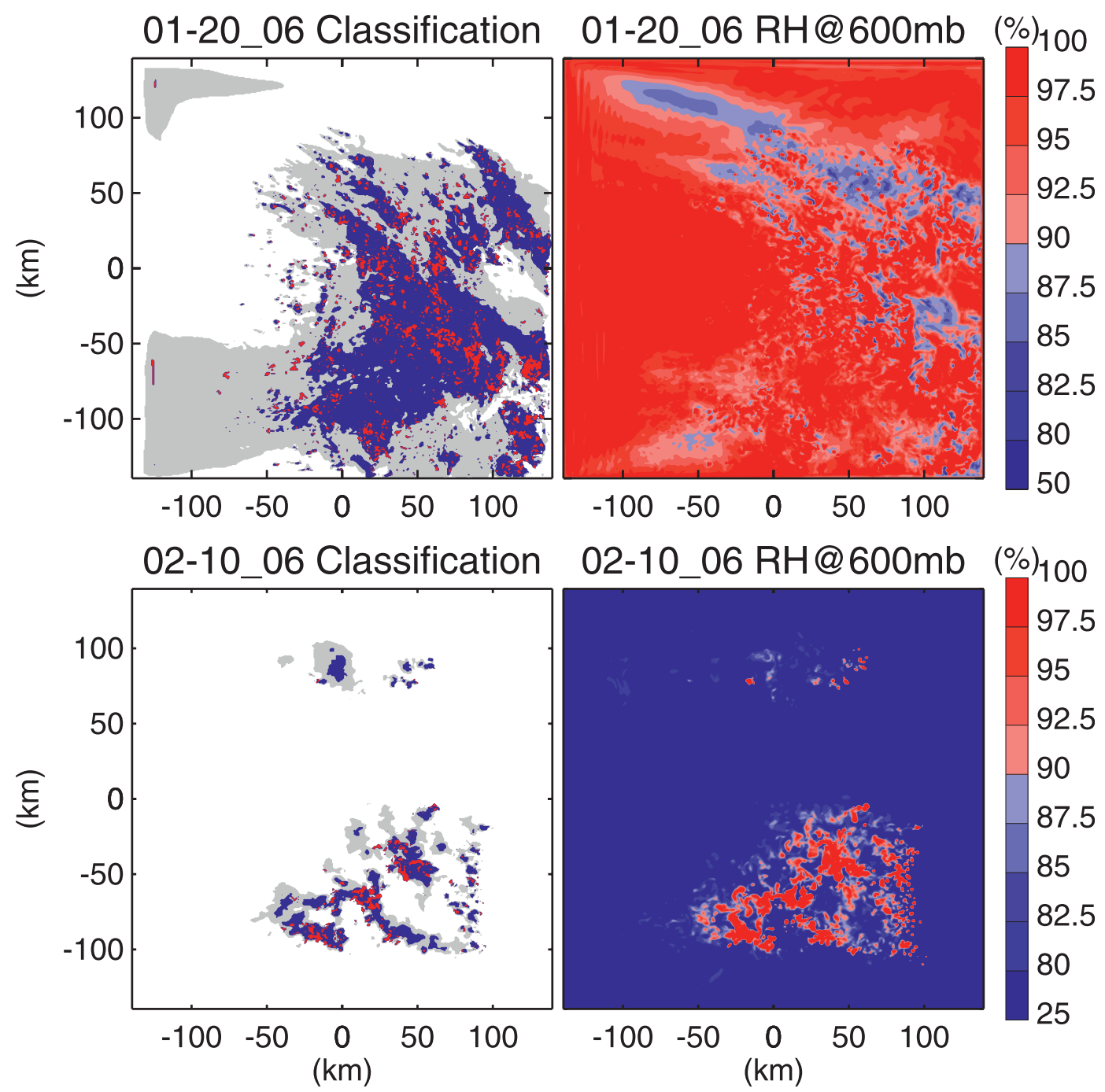

FIG. 16. (Left) CU/TR/SR classification as in Fig. 3 and (right) 600-hPa RH during the (top) active and (bottom) break periods.

surrounding the convective updrafts is actually slightly drier in some places (see also Table 2). However, during the drier break period (bottom panels), the area of very humid air is broader than that of the updrafts, covering most of the TR area, presumably due to rain evaporation and the transfer of air out of the cloud during earlier detrainment episodes. TR air entrained into convective updrafts is $12 \%$ drier than the air inside the $\mathrm{CU}$ region but $16 \%$ wetter than the domain mean RH (Table 2). Thus, the efficacy of entrainment-its ability to reduce parcel buoyancy-is reduced in the vicinity of deep convective clouds. Such "humidity halos" have been observed adjacent to shallow cumulus clouds (e.g., Laird 2005).

To our knowledge the only representation of mesoscale vertical motions in an operational GCM is the scheme of Donner (1993) and Donner et al. (2001), but their mesoscale vertical velocities are prescribed and applied at the same time as the convection and thus do not simulate life cycle evolution. To add memory, a parameterization must represent the energy and moisture budgets that determine the mesoscale contributions to

TABLE 2. 600-hPa mean RH (\%) over different parts of the domain for the simulated active monsoon and monsoon break periods using the Morrison et al. (2009) microphysics. Three columns for each period represent the control, no-shear, and nested grid simulations, respectively.

\begin{tabular}{lcccccc}
\hline \hline Region & \multicolumn{3}{c}{ Active monsoon } & \multicolumn{3}{c}{ Monsoon break } \\
\hline CU & 98.8 & 99.2 & 98.3 & 94.4 & 94.9 & 93.3 \\
TR & 96.3 & 96.7 & 96.2 & 82.2 & 87.6 & 79.9 \\
SR & 96.0 & 95.2 & 96.0 & 77.3 & 80.9 & 74.1 \\
Domain & 96.5 & 95.8 & 94.5 & 66.4 & 71.8 & 60.1 \\
\hline
\end{tabular}


the apparent heat source $Q_{1}$ and apparent moisture sink $Q_{2}$ and the evolution of vertical velocity, area, and hydrometeor mixing ratio. It should do so in a way that allows the mesoscale dynamics to be responsive, both to the strength of the convection (Fig. 14) and to the properties of the environment (Fig. 13).

Figure 10 provides constraints on the mesoscale energy budget. Air in the TR region is buoyant, suggesting that it is detrained from the $\mathrm{CU}$ region; this is also supported by its spatial relationship to the CU region (Fig. 3), the several meters-per-second peak updraft speeds there (Fig. 11), and the consistent correlation of its properties with those of the CU region with small lags (Figs. 14 and 15). In contrast, the SR region air is only weakly buoyant (Fig. 10), consistent with its much weaker updraft speeds (Fig. 11). Combined with the fact that TR and SR updraft speeds are highly correlated with CU updraft speed and mass flux at small lags, this behavior of the WRF indicates that a fraction of the rising convective air is detrained and could be used to initialize a parameterized mesoscale updraft speed $\omega_{m}$ (see, e.g., section 9.2 of Houze 1993; Gray 2000). Given the nearly neutral buoyancy of the SR region above the melting level though, the subsequent evolution of $\omega_{m}$ should be dictated by the requirement that adiabatic cooling balance the combined latent heating and radiative heating/cooling that results from condensation and deposition in the updraft plus any deposition growth of sedimenting ice crystals in the environment below the detrainment level (if the environment is ice supersaturated).

This appears to be what differentiates SR evolution in our active and break simulations (Fig. 13, top panels; Fig. 14). Sedimenting ice sublimes in the drier $(\sim 55 \%$ $\mathrm{RH}$ with respect to liquid water) break upper-troposphere environment; so, once convective detrainment terminates, the SR region decays. In the moist (nearly saturated with respect to liquid water) active environment though, sedimenting ice can survive or continue to grow by deposition, and the resulting latent heating helps sustain $\omega_{m}$ for several hours more. The 5-6-h lag between the SR area and the CU mass flux in our active simulations (Fig. 14 , top panels) is comparable to the time it takes for ice particles with a typical fall speed of $\sim 0.5 \mathrm{~m} \mathrm{~s}^{-1}$ to sediment $\sim 10 \mathrm{~km}$ from the upper troposphere to the melting level. The implication is that SR area growth should be parameterized as a function of the detrainment mass source, and then offset by a sink initiated when ice loss by sedimentation begins to outweigh deposition growth. Similar considerations should apply to driving a mesoscale downdraft via the cooling from melting and evaporation.

Capturing these features of the life cycle may be the true test of the fidelity of parameterized microphysics in models-not only GCMs, but CRMs. (Note that snow is not a prognostic variable in current GCMs, which prevents them from even creating a mesoscale anvil whose base extends down to the melting level.) A useful test of GCM microphysics might then be whether 1) organization produces a life cycle of developing, mature, and dissipating stages as seen in TRMM satellite data (Futyan and Del Genio 2007) and surface radar data (e.g., Frederick and Schumacher 2008); 2) the stratiform heating/cooling pattern resembles TRMM retrievals (Fig. 1), and 3) the mesoscale updraft speeds are stronger than grid-scale vertical motions but weaker than the fall speed of snow, the defining characteristic of the stratiform region (Biggerstaff and Houze 1991).

The preceding discussion is necessarily thermodynamic in nature because of the weak wind shear conditions that prevailed during the TWP-ICE periods we examined. There is a long history of evidence for the controlling influence of wind shear and the momentum budget on convective cluster evolution in stronger shear environments (Rotunno et al. 1988; Tao and Moncrieff 2009). We regard this as a more challenging problem, since a GCM cannot directly anticipate relevant features such as cluster morphology (squall vs nonsquall), orientation, and propagation direction and speed. However, the general features of what such a parameterization framework might look like have been laid out by Moncrieff (1992). Experiments similar to ours should be performed with other CRMs and in other climate regimes to determine how robust the behavior we report is. New opportunities for observation of the microphysics and dynamics of mesoscale clusters also now exist with the advent of arrays of Doppler radars and lidars that can better constrain a three-dimensional cloud and rain structure and its temporal evolution, as well as the dynamics and microphysical properties of the clouds. Recent examples of these new capabilities such as the Midlatitude Continental Convective Clouds Experiment (http:// campaign.arm.gov/mc3e/ and http://mc3e.nsstc.nasa. gov/) promise to provide useful tests for both CRMs and GCM parameterizations that are based on them.

Acknowledgments. This research was supported by the NASA Precipitation Measurement Missions program, the DOE Atmospheric System Research and FASTER programs, and the NASA Modeling, Analysis, and Prediction program. We thank two anonymous reviewers for their constructive suggestions, which improved the paper.

\section{REFERENCES}

Ackerman, T. P., K.-N. Liou, F. P. J. Valero, and L. Pfister, 1988: Heating rates in tropical anvils. J. Atmos. Sci., 45, 1606-1623. 
Alexander, G. D., and W. R. Cotton, 1998: The use of cloudresolving simulations of mesoscale convective systems to build a mesoscale parameterization scheme. J. Atmos. Sci., 55, $2137-$ 2161.

Arakawa, A., and W. H. Schubert, 1974: Interaction of a cumulus cloud ensemble with the large-scale environment, Part I. J. Atmos. Sci., 31, 674-701.

Atlas, D., C. W. Ulbrich, F. D. Marks Jr., E. Amitai, and C. R. Williams, 1999: Systematic variation of drop size and radarrainfall relations. J. Geophys. Res., 104 (D6), 6155-6169.

Biggerstaff, M. I., and R. A. Houze Jr., 1991: Kinematic and precipitation structure of the 10-11 June 1985 squall line. Mon. Wea. Rev., 119, 3034-3065.

Bouniol, D., J. Delanoë, C. Duroure, A. Protat, V. Giraud, and G. Penide, 2010: Microphysical characterisation of West African MCS anvils. Quart. J. Roy. Meteor. Soc., 136, 323-344.

Braun, S. A., and R. A. Houze Jr., 1994: The transition zone and secondary maximum of radar reflectivity behind a midlatitude squall line: Results retrieved from Doppler radar data. J. Atmos. Sci., 51, 2733-2755.

Bryan, G. H., J. C. Wyngaard, and J. M. Fritsch, 2003: Resolution requirements for the simulation of deep moist convection. Mon. Wea. Rev., 131, 2394-2416.

Cetrone, J., and R. A. Houze Jr., 2011: Leading and trailing anvil clouds of West African squall lines. J. Atmos. Sci., 68, 1114-1123.

Chen, F., and J. Dudhia, 2001: Coupling an advanced land surfacehydrology model with the Penn State-NCAR MM5 modeling system. Part I: Model implementation and sensitivity. Mon. Wea. Rev., 129, 569-585.

Chou, M.-D., and M. J. Suarez, 1994: An efficient thermal infrared radiation parameterization for use in general circulation models. Tech. Rep. Series on Global Modeling and Data Assimilation, NASA Tech. Memo. NASA/TM-104606, Vol. 3, $85 \mathrm{pp}$.

Dai, A., 2006: Precipitation characteristics in eighteen coupled climate models. J. Climate, 19, 4605-4630.

Del Genio, A. D., and W. Kovari, 2002: Climatic properties of tropical precipitating convection under varying environmental conditions. J. Climate, 15, 2597-2615.

—, and $\mathrm{J} . \mathrm{Wu}, 2010$ : The role of entrainment in the diurnal cycle of continental convection. J. Climate, 23, 2722-2738.

_- A. A. Lacis, and R. A. Ruedy, 1991: Simulations of the effect of a warmer climate on atmospheric humidity. Nature, $\mathbf{3 5 1}$, 382-385.

_ M.-S. Yao, W. Kovari, and K. K.-W. Lo, 1996: A prognostic cloud water parameterization for global climate models. J. Climate, 9, 270-304.

— W. Kovari, M.-S. Yao, and J. Jonas, 2005: Cumulus microphysics and climate sensitivity. J. Climate, 18, 2376-2387.

_ M.-S. Yao, and J. Jonas, 2007: Will moist convection be stronger in a warmer climate? Geophys. Res. Lett., 34, L16703, doi:10.1029/2007GL030525.

Donner, L. J., 1993: A cumulus parameterization including mass fluxes, vertical momentum dynamics, and mesoscale effects. J. Atmos. Sci., 50, 889-906.

— C. J. Seman, R. S. Hemler, and S. Fan, 2001: A cumulus parameterization including mass fluxes, vertical momentum dynamics, and mesoscale effects: Thermodynamic and hydrological aspects in a general circulation model. J. Climate, 14, 3444-3463.

Emanuel, K. A., J. D. Neelin, and C. S. Bretherton, 1994: On largescale circulations in convecting atmospheres. Quart. J. Roy. Meteor. Soc., 120, 1111-1143.
Frederick, K., and C. Schumacher, 2008: Anvil characteristics as seen by C-POL during the Tropical Warm Pool International Cloud Experiment (TWP-ICE). Mon. Wea. Rev., 136, 206-222.

Fridlind, A. M., and Coauthors, 2012: A comparison of TWP-ICE observational data with cloud-resolving model results. J. Geophys. Res., 117, D05204, doi:10.1029/2011JD016595.

Futyan, J. M., and A. D. Del Genio, 2007: Deep convective system evolution over Africa and the tropical Atlantic. J. Climate, 20, 5041-5060.

Grandpeix, J.-Y., and J.-P. Lafore, 2010: A density current parameterization coupled with Emanuel's convection scheme. Part I: The models. J. Atmos. Sci., 67, 881-897.

$\longrightarrow,-$, and F. Cheruy, 2010: A density current parameterization coupled with Emanuel's convection scheme. Part II: 1D simulations. J. Atmos. Sci., 67, 898-922.

Gray, M. E. B., 2000: Characteristics of numerically simulated mesoscale convective systems and their application to parameterization. J. Atmos. Sci., 57, 3953-3970.

Guichard, F., and Coauthors, 2004: Modelling the diurnal cycle of deep precipitating convection over land with cloud-resolving models and single-column models. Quart. J. Roy. Meteor. Soc., 130, 3139-3172.

Hagos, S., and Coauthors, 2010: Estimates of tropical diabatic heating profiles: Commonalities and uncertainties. J. Climate, 23, 542-558.

Houston, A. L., and R. B. Wilhelmson, 2011: The dependence of storm longevity on the pattern of deep convection initiation in a low-shear environment. Mon. Wea. Rev., 139, 3125-3138.

Houze, R. A., Jr., 1989: Observed structure of mesoscale convective systems and implications for large-scale heating. Quart. J. Roy. Meteor. Soc., 115, 425-461.

1993: Cloud Dynamics. Academic Press, 573 pp.

2004: Mesoscale convective systems. Rev. Geophys., 42, RG4003, doi:10.1029/2004RG000150.

, and A. K. Betts, 1981: Convection in GATE. Rev. Geophys. Space Phys., 19, 541-576.

Janjić, Z. I., 2002: Nonsingular implementation of the MellorYamada level 2.5 scheme in the NCEP meso model. NCEP Office Note 437, 61 pp.

Jensen, M. P., and A. D. Del Genio, 2003: Radiative and microphysical characteristics of deep convective systems in the tropical western Pacific. J. Appl. Meteor., 42, 1234-1254.

Kain, J. S., 2004: The Kain-Fritsch convective parameterization: An update. J. Appl. Meteor., 43, 170-181.

Khairoutdinov, M., and D. Randall, 2006: High-resolution simulation of shallow-to-deep convection transition over land. J. Atmos. Sci., 63, 3421-3436.

Kim, D., and Coauthors, 2009: Application of MJO simulation diagnostics to climate models. J. Climate, 22, 6413-6436.

Kuang, Z., and C. S. Bretherton, 2006: A mass-flux scheme view of a high-resolution simulation of a transition from shallow to deep cumulus convection. J. Atmos. Sci., 63, 1895-1909.

Laird, N. F., 2005: Humidity halos surrounding small cumulus clouds in a tropical environment. J. Atmos. Sci., 62, 3420-3425.

L'Ecuyer, T. S., and G. McGarrah, 2010: A 10-year climatology of tropical radiative heating and its vertical structure from TRMM observations. J. Climate, 23, 519-541.

Lin, J.-L., and Coauthors, 2006: Tropical intraseasonal variability in 14 IPCC AR4 climate models. Part I: Convective signals. J. Climate, 19, 2665-2690.

Mapes, B. E., 2000: Convective inhibition, subgrid-scale triggering energy, and stratiform instability in a toy tropical wave model. J. Atmos. Sci., 57, 1515-1535. 
— , and R. B. Neale, 2011: Parameterizing convective organization to escape the entrainment dilemma. J. Adv. Model. Earth Syst., 3, M06004, doi:10.1029/2011MS000042.

— S. Tulich, J. Lin, and P. Zuidema, 2006: The mesoscale convection life cycle: Building block or prototype for large-scale tropical waves? Dyn. Atmos. Oceans, 42, 3-29.

Mather, J. H., and S. A. McFarlane, 2009: Cloud classes and radiative heating profiles at the Manus and Nauru Atmospheric Radiation Measurement (ARM) sites. J. Geophys. Res., 114, D19204, doi:10.1029/2009JD011703.

May, P. T., and D. K. Rajopadhyaya, 1999: Vertical velocity characteristics of deep convection over Darwin, Australia. Mon. Wea. Rev., 127, 1056-1071.

_ , J. H. Mather, G. Vaughan, C. Jakob, G. M. McFarquhar, K. N. Bower, and G. G. Mace, 2008: The Tropical Warm Pool International Cloud Experiment. Bull. Amer. Meteor. Soc., 89, 629-645.

Mlawer, E. J., S. J. Taubman, P. D. Brown, M. J. Iacono, and S. A. Clough, 1997: Radiative transfer for inhomogeneous atmosphere: RRTM, a validated correlated-k model for the longwave. J. Geophys. Res., 102 (D14), 16 663-16 682.

Moncrieff, M. W., 1992: Organized convective systems: Archetypal dynamical models, mass and momentum flux theory, and parameterization. Quart. J. Roy. Meteor. Soc., 118, 819-850.

Morrison, H., G. Thompson, and V. Tatarskii, 2009: Impact of cloud microphysics on the development of trailing stratiform precipitation in a simulated squall line: Comparison of oneand two-moment schemes. Mon. Wea. Rev., 137, 991-1007.

Piriou, J.-M., J.-L. Redelsperger, J.-F. Geleyn, J.-P. Lafore, and F. Guichard, 2007: An approach for convective parameterization with memory: Separating microphysics and transport in grid-scale equations. J. Atmos. Sci., 64, 4127-4139.

Qian, L., G. S. Young, and W. M. Frank, 1998: A convective wake parameterization scheme for use in general circulation models. Mon. Wea. Rev., 126, 456-469.

Rio, C., F. Hourdin, J.-Y. Grandpeix, and J.-P. Lafore, 2009: Shifting the diurnal cycle of parameterized deep convection over land. Geophys. Res. Lett., 36, L07809, doi:10.1029/ 2008GL036779.

Romps, D. M., and Z. Kuang, 2010: Do undiluted convective plumes exist in the upper tropical troposphere? J. Atmos. Sci., 67, 468-484.

Rotunno, R., J. B. Klemp, and M. L. Weisman, 1988: A theory for strong, long-lived squall lines. J. Atmos. Sci., 45, 463-485.

Schumacher, C., and R. A. Houze Jr., 2003: Stratiform rain in the tropics as seen by the TRMM precipitation radar. J. Climate, 16, 1739-1756.

— Saharan Africa and the tropical east Atlantic as observed by TRMM. Quart. J. Roy. Meteor. Soc., 132, 2235-2255.

,$- \ldots$, and I. Kraucunas, 2004: The tropical dynamical response to latent heating estimates derived from the TRMM precipitation radar. J. Atmos. Sci., 61, 1341-1358.

Shige, S., Y. N. Takayabu, W.-K. Tao, and C.-L. Shie, 2007: Spectral retrieval of latent heating profiles from TRMM PR data. Part II: Algorithm improvement and heating estimates over tropical ocean regions. J. Appl. Meteor. Climatol., 46, 1098-1124.

Skamarock, W. C., and Coauthors, 2008: A description of the Advanced Research WRF version 3. NCAR Tech. Note NCAR/TN-475+STR, 113 pp.

Tao, W.-K., and M. W. Moncrieff, 2009: Multiscale cloud system modeling. Rev. Geophys., 47, RG4002, doi:10.1029/2008RG00 0276.

—- and Coauthors, 2001: Retrieved vertical profiles of latent heat release using TRMM rainfall products for February 1998. J. Appl. Meteor., 40, 957-982.

Thompson, G., P. R. Field, R. M. Rasmussen, and W. D. Hall, 2008: Explicit forecasts of winter precipitation using an improved bulk microphysics scheme. Part II: Implementation of a new snow parameterization. Mon. Wea. Rev., 136, 5095-5115.

Tompkins, A. M., 2001: Organization of tropical convection in low vertical wind shears: The role of cold pools. J. Atmos. Sci., 58, $1650-1672$.

Varble, A., and Coauthors, 2011: Evaluation of cloud-resolving model intercomparison simulations using TWP-ICE observations: Precipitation and cloud structure. J. Geophys. Res., 116, D12206, doi:10.1029/2010JD015180.

Wu, J., A. D. Del Genio, M.-S. Yao, and A. B. Wolf, 2009: WRF and GISS SCM simulations of convective updraft properties during TWP-ICE. J. Geophys. Res., 114, D04206, doi:10.1029/ 2008JD010851.

Wu, L., and G. W. Petty, 2010: Intercomparison of bulk microphysics schemes in model simulations of polar lows. Mon. Wea. Rev., 138, 2211-2288.

Xie, S., T. Hume, C. Jakob, S. A. Klein, R. B. McCoy, and M. Zhang, 2010: Observed large-scale structures and diabatic heating and drying profiles during TWP-ICE. J. Climate, 23, $57-79$.

Yao, M.-S., and A. D. Del Genio, 1999: Effects of cloud parameterization on the simulation of climate changes in the GISS GCM. J. Climate, 12, 761-779.

Yuter, S. E., and R. A. Houze Jr., 1998: The natural variability of precipitating clouds over the western Pacific warm pool. Quart. J. Roy. Meteor. Soc., 124, 53-99.

Zelinka, M. D., and D. L. Hartmann, 2009: Response of humidity and clouds to tropical deep convection. J. Climate, 22, 23892404.

— J. Geophys. Res., 115, D16117, doi:10.1029/2010JD013817.

Zhu, P., and Coauthors, 2012: A limited area model (LAM) intercomparison study of a TWP-ICE active monsoon mesoscale convective event. J. Geophys. Res., 117, D11208, doi:10.1029/ 2011JD016447.

Zipser, E. J., 1977: Mesoscale and convective-scale downdrafts as distinct components of squall-line structure. Mon. Wea. Rev., 105, 1568-1589.

_ , and K. R. Lutz, 1994: The vertical profile of radar reflectivity of convective cells: A strong indicator of storm intensity and lightning probability? Mon. Wea. Rev., 122, 1751-1759. 